\title{
Article \\ Improving Ship Maneuvering Safety with Augmented Virtuality Navigation Information Displays
}

\author{
Rafał Gralak*(D), Bartosz Muczyński (D) and Marcin Przywarty (D) \\ Faculty of Navigation, Maritime University of Szczecin, 70-500 Szczecin, Poland; \\ b.muczynski@am.szczecin.pl (B.M.); m.przywarty@am.szczecin.pl (M.P.) \\ * Correspondence: r.gralak@am.szczecin.pl
}

check for updates

Citation: Gralak, R.; Muczyński, B.; Przywarty, M. Improving Ship

Maneuvering Safety with Augmented Virtuality Navigation Information Displays. Appl. Sci. 2021, 11, 7663. https://doi.org/10.3390/app11167663

Academic Editors: Cezary Specht, Peter Vidmar and Grzegorz Stępień

Received: 7 July 2021

Accepted: 18 August 2021

Published: 20 August 2021

Publisher's Note: MDPI stays neutral with regard to jurisdictional claims in published maps and institutional affiliations.

Copyright: (c) 2021 by the authors. Licensee MDPI, Basel, Switzerland. This article is an open access article distributed under the terms and conditions of the Creative Commons Attribution (CC BY) license (https:/ / creativecommons.org/licenses/by/ $4.0 /)$.
Featured Application: The presented study can be applied to increase the safety of navigation using augmented virtuality decision support systems. It can also be used for comparison for other studies involving the use of mixed reality devices and interfaces for the safety of ships' navigation.

\begin{abstract}
The paper presents the results of a study on improving the safety of navigation, during maneuvers in restricted areas, with the use of an augmented virtuality navigation information display. The augmented virtuality solution has been developed by one of the authors and has been described in a previous paper. A set of simulation scenarios has been proposed to study various maneuvers with different types of ships. Models of existing areas and existing ships have been used so the study can be recreated and reevaluated with different types of interfaces. The study is focused on comparing safe maneuvering areas with different information sources used. The results showed that augmented virtuality solution can indeed decrease the safe maneuvering areas and thus increase the safety of navigation for maneuvers in restricted areas.
\end{abstract}

Keywords: augmented virtuality; decision support system; safety of navigation; marine simulation; MASS

\section{Introduction}

Technological development and demonstration projects for autonomous shipping have been carried out around the world since the 1990s. Although fully robotic ships are distant in the future, it is not in doubt whether they will arise, but when [1].

There is a growing interest in the topic of unmanned, fully autonomous ships. This idea could be a milestone in the advancement of the maritime industry. The concept of Unmanned Autonomous Vehicles UAV or, more precisely, Unmanned Maritime Vehicles [2], has been well known at an academic level for a while. Recently, the industry has begun developing small-scale [3] and full-scale vessels for the bulk [4-9], container [10-14], ferry [15-17], inland [18-20], offshore [21] and tug [22-24] sectors. Detailed surveys [25] were presented in the scope of: the opportunities in logistics [26], the development of autonomous technologies [27] and the accuracy in performing planned trajectories [28].

An unmanned ship is defined by the bridge being unmanned in periods (periodically) or continuously. This may be performed with the help of autonomy but may also be implemented by direct remote control. Thus, autonomous and unmanned are at least partly independent. The degree of advancement of technological solutions and the level of crew reduction adopted in the currently implemented UMV projects categorize them into specific automation ranges. The categorization of systems in terms of the level of advancement of technological solutions was proposed by: Lloyd's Register [29], RollsRoyce [30], Bureau Veritas, Norwegian Forum for Autonomous Ships (NFAS), Ramboll and Core, UK Marine Industries Alliance [31], assuming the lowest level of automation as "All action and decision-making performed manually" and the highest as "The computer does everything autonomously, operation are unsupervised by a human". On the other hand, 
the ranges of automation resulting from the presence of the ship's crew and the general approach to the problem were presented [2].

The official classification of the UMV, which was officially named Marine Autonomous Surface Ships (MASS), in terms of automation level of the applied system, is presented in the working group report of IMO Maritime Safety Committee 100th session MSC 100/WP.8. According to this scale, degree 1 of autonomy involves seafarers onboard to operate and control the shipboard systems and functions. Under degrees 2 and 3, the ship is controlled and operated by remote control operators from another location. Seafarers are available onboard to take control in degree 2, whereas the ship is unmanned and remotely controlled in degree 3 . In degree 4 , the ship is fully autonomous as the operating system will be able to make decisions and determine actions by itself and operate independently of direct human interaction [32].

The analysis of voyage phases of modern UMVs from the point of view of human presence on board showed that the passage of the ship in a restricted area as well as mooring, unberthing and turning maneuvers will not be fully automatic in the near future without assurance of emergency management, monitoring and taking over the remote control. This is due to a number of limitations or the inability to perform the tasks [26], including ensuring safe e-navigation by fully autonomous systems during maneuvers in restricted areas $[2,6,30]$.

Due to the above, the institutions involved in the legislative process accompanying the development of the autonomous ships sector developed and implemented a number of guidelines for MASS operation. The most important of them have been published by, among others: IMO [33,34], DNV [35], EMSA [36] or ClassNK [37].

The guidelines indicate, inter alia, that for tests of autonomous and remote-controlled ships in restricted areas, it is required to monitor the parameters of the vessel's movement by the Remote Operation Station (ROC) in an efficient and effective way. The tools used should provide a high level of situational awareness (SA) to the MASS operator. In the case of navigation in a restricted area, enable the remote vessel to be controlled, and in case of an emergency, enable it to take full control of the autonomous vessel. The system that performs this task is referred to as an unmanned look-out [6].

Remote-controlled ships interact and communicate with human-operated systems. In this way, human operators carry out an e-navigation and continuously monitor the vessel from the ROC to avoid accidents. The onboard systems follow well-established international regulations, whereas the implementation of ROCs is not standardized, and companies develop their own [38].

The system must ensure a proper lookout at all times [35]. The ROC e-navigation system must be at least equivalent to the function of an on-board human look-out as per COLREGs Rule 5, SOLAS Reg. 24, and the STCW. For monitoring and remote control, it is enough that the system transfers sufficient visual and sound data to the ROC.

The level of the operator's situational awareness in the ROC in terms of the ship's position in space depends largely on the type of navigation information and the form of its presentation, i.e., generally on the Human-Machine Interface (HMI) used. A literature review from the maritime perspective, based on solutions from various areas of HMI, is presented [38].

The analysis of the literature of the MASS systems listed in this section in terms of the tools used in Autonomous Navigation Systems (ANS) showed that the most frequently used Human-Machine Interface used in e-navigation to provide situational awareness to the operator in terms of the position and orientation of the ship in restricted areas are:

- top-view, two-dimensional graphic representation of the ship (popular in ECDIS, DP and pilot systems) enriched with alphanumeric data obtained from sensors fusion;

- cameras image enriched with elements in augmented reality technology (AR).

Research shows that the current e-navigation systems used in ROC provide a limited scope for the SA, as expressed in the model Goal-Based Gap Analysis (GBGA) [39] and research on human factor issues for autonomous ships purposes [38,40-42]. 
The report of the 58th session of the Subcommittee on Navigation Safety (NAV) [43] also refers to SA in its discussion of various user gaps and initial potential solutions for the operational areas of e-navigation solutions; some of the solutions identified could possibly also be applied to the field of MASS, for instance, the integrated presentation of available information. Research has shown that there is no harmonized presentation of local information to increase SA for ROC services for remote vessel operation [6].

It was noted that on-board navigation systems could, for example, benefit from better integration of own ship sensors and standard user interfaces, while the shore management could benefit from more comprehensive but easily understandable data provided by a seamless information transfer [6,30] or by its augmentation with the use of 3D Mixed Reality (MR) features [22].

MR technology allows the ship's environment to be recreated in 3D on shore from real-time ship data. This can be conducted using no more data than the current data sent to the ROC. By placing the ship into a 3D recreation of the world, one can gain SA in a more natural and traditional way by developing an enhanced understanding of the 3D space surrounding the ship. This will facilitate a smoother transition into an actual reality provided during direct control and other real-time video transfers by reducing the psychological distance and increase distance measurements $[44,45]$.

With regard to the above authors present, a navigational information real-time Augmented Virtuality (AV-the component of MR) display method, using geometric 3D virtual models, created at the stage of system's database development, shown in a perspective and/or parallel 2D view on an electronic device screen. The method assumes a possibly faithful representation of the environment and the actual SA via the ROC Decision Support System (DSS) interface during the ship maneuvers in a restricted area. A detailed description of the method was presented to the reader in the previous publication [46]. This paper presents a study of the impact of the method of navigational information display using augmented virtuality on the safety of navigation for selected vessels, whose types are currently the subject of research in the field of MASS.

\section{Methodology}

It was impossible to investigate the impact of the method of displaying navigation information in the technology of augmented virtuality on the safety of maneuvers in real conditions. Maneuvering the ship in real conditions on the basis of information obtained only from the use of the described method was unacceptable in terms of the safety of the maneuvering ship. Moreover, conducting such tests in the prototype phase was economically unjustified.

Due to the above, in order to investigate the influence of the method of displaying navigation information in the technology of augmented virtuality on the safety of maneuvers performed on the basis of indications of the spatial decision support system (SDSS), a simulation experiment was carried out.

The experiment consisted of the performance by 20 navigators with a valid watch officer or captain diploma of a series of separate trials using the simulation environment model and other sources of navigation information commonly available on the bridge in various maneuvering scenarios. The traffic parameters recorded during the trials were subjected to comparative analysis in terms of selected navigation safety criteria. All simulation trials took place in local waters, well-known to each participant of the study.

\subsection{Test Bed}

The simulation tests were carried out on a certified Polaris Navigation and Maneuvering Simulator by Kongsberg Maritime AS (Kongsberg, Norway), located at the Department of Marine Simulations at the Maritime University of Szczecin. The maneuvering simulator with an implemented simulation model of the vessel's movement was equipped, in addition to standard navigation and maneuvering devices and visual station for environment imaging, SDSS such as: 
1. The ECDIS decision support system in the form of the electronic navigational chart (ENC), 1:4000 scale (Figure 1a);

2. The system of decision support with navigational display, with parallel top view projection, with a maximum contour of the vessel, was preliminarily called (Pmax) (Figure 1b);

3. The system of decision support with navigational display, realized in the parallel top view projection, with the contour of the vessel on the theoretical plane of contact with the shore, labeled Pilot_precise (Pprecise) (Figure 1c);

4. The spatial decision support system with the implemented display method in augmented virtuality technology, denoted by AV (Figure 1d), the construction of which has been described [46].

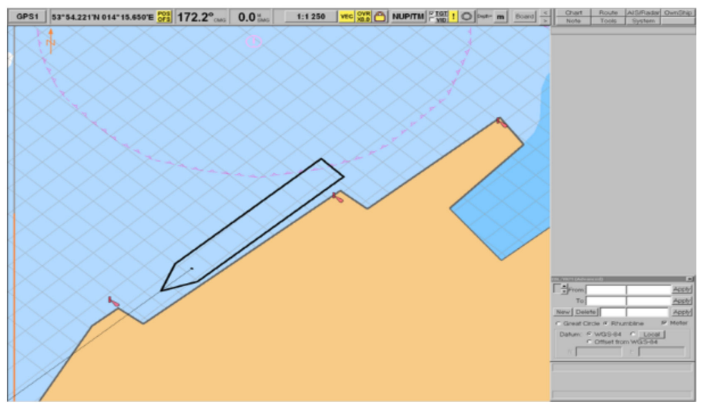

(a)

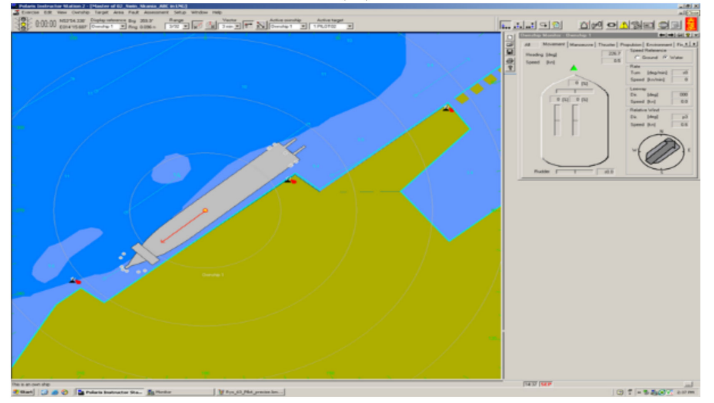

(c)

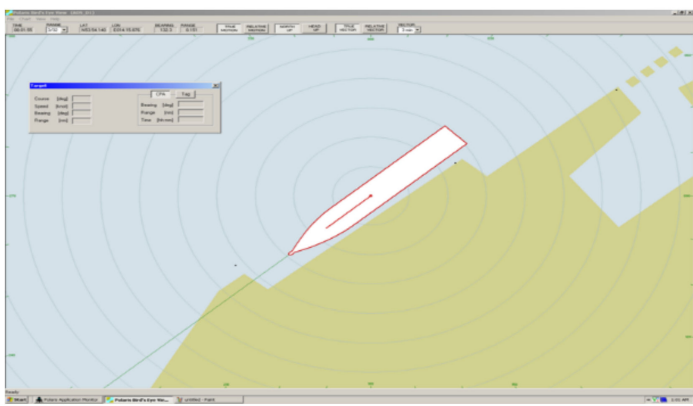

(b)

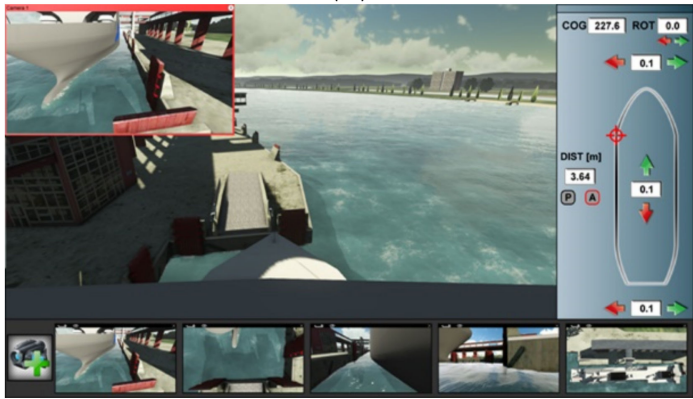

(d)

Figure 1. SDSS used in simulation studies: (a) ECDIS, (b) Pilot_max, (c) Pilot_precise and (d) AV.

The test stand used in the simulation studies is shown in Figure 2.

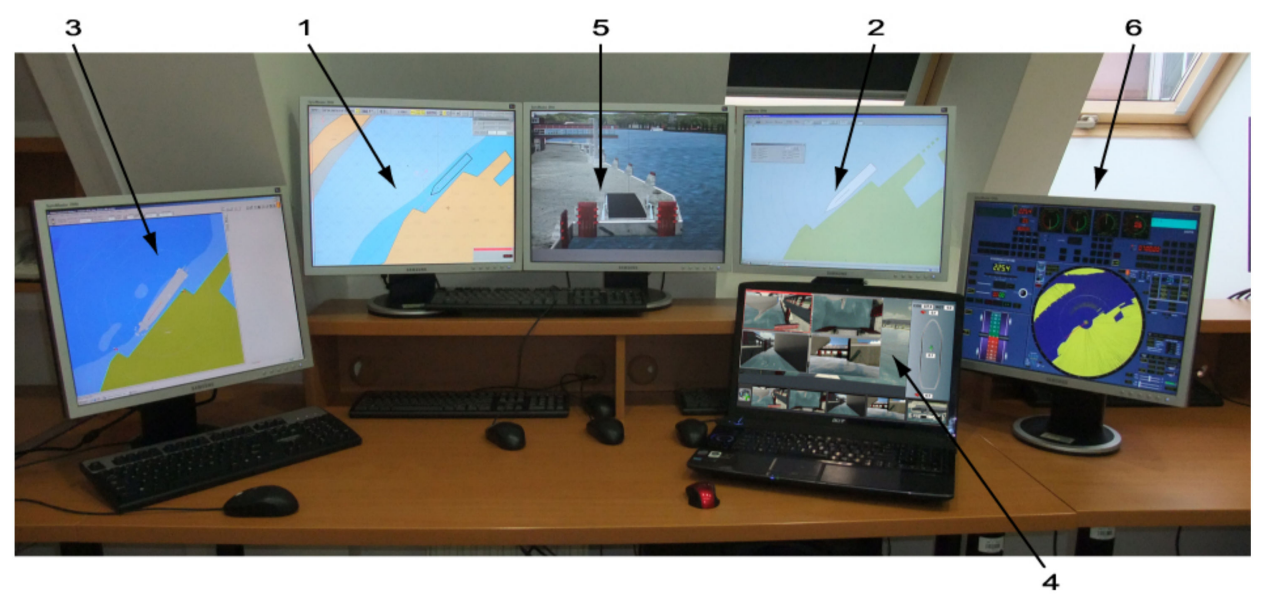

Figure 2. The test stand used by navigators during simulation studies: (1) ECDIS, (2) Pilot_max, (3) Pilot_precise, (4) AV, (5) visual station and (6) other Integrated Bridge Systems. 
In order to eliminate errors in the indications of individual SDSSs, the process of calibration and verification of their indications in terms of mapping the shape and scale of objects as well as their position and orientation was carried out. This process consisted of exporting databases to one graphic environment, where the shape and scale of each object were verified. The re-exported objects were verified in terms of the correctness of their position and orientation, using the navigation tools built into individual decision support systems.

\subsection{Navigation Safety Assessment Criteria}

To conduct a simulation experiment with the use of the navigator's spatial decision support system with the implemented method of displaying information in AV technology, detailed and general research assumptions were defined.

Depending on the variant of the runs in the simulation experiment (described in detail later in this section), the following criteria were adopted as a measure of the evaluation of a series of simulation tests:

1. The primary (superior) criteria for the assessment of navigational safety, i.e.,:

a. the average maneuvering area of the ship estimated for the confidence coefficient 0.95 , determined by the estimation of the interval boundaries, which at $95 \%$ probability will cover the true value of the mean distance from the reference point center;

b. maximum maneuvering area of the ship, where the calculation is based on the determination of maximum distances of ship's contour points in a given sector, from the determined coordinate of the center of the adopted reference point and using those for further analysis;

c. resultant value of vessel's speed determined at the moment of ship's hull contact with a fender (modified criterion of the kinetic energy of the first contact with the shore);

d. the value of the minimum distance of the ship's hull from the navigational obstacle.

2. Secondary (subordinate) criterion for assessing the efficiency of maneuvering, i.e., maneuvering time.

3. The secondary criterion of assessment of the maneuvering efficiency was applied in the analysis when it was impossible to unequivocally assess recorded movement parameters using the primary criterion.

\subsection{Detailed Assumptions of Simulation Study (Simulation Scenarios)}

The simulation study utilized models of real ships; their parameters can be found in any generally available database of merchant ships. Maneuvering variants for the constructed models of ships, corresponding to the actual navigational situations in the studied waters, were determined with the use of an expert survey method. The study consisted of assigning five different types of maneuvers to the given units, using the existing devices of the integrated bridge and the developed spatial decision support system with the implemented method of imaging in AV technology, which, according to the expert, were the most appropriate to be performed in the studied area, which was the port of Świnoujście, located in the north-western part of Poland, in the Baltic Sea basin. The number of questionnaires was defined as $n=20$. Each time the study was preceded by the expert acquainting with the developed method.

The analysis of the results of the expert study made it possible to identify variants of maneuvers carried out under the scenarios in the simulation experiment in question. The scenarios were built, taking into account the maneuvers with the highest scores for a given unit. For the towed train, 2 variants with the highest scores were adopted: unberthing and turning. The unit-simulation maneuver configuration matrix is presented in Table 1. 
Table 1. The matrix of vessel-simulated maneuver configurations.

\begin{tabular}{ccccccccc}
\hline Vessel Type/Name & \multicolumn{7}{c}{ The Matrix of Vessel-Simulated Maneuver Configurations } \\
\hline $\begin{array}{c}\text { Container ship/ } \\
\text { m/v "Green Breeze" }\end{array}$ & 1 & 3 & - & - & - & $\mathbf{8}$ & 3 & 5 \\
\hline $\begin{array}{c}\text { General cargo ship/ } \\
\text { "Arklow River;" }\end{array}$ & 1 & 2 & 3 & $\mathbf{9}$ & - & 2 & 1 & 2 \\
\hline $\begin{array}{c}\text { Sea ferry/ } \\
\text { m/f "Skania"; }\end{array}$ & 1 & 1 & - & - & 7 & 4 & 3 & 4 \\
\hline $\begin{array}{c}\text { Cruise ship/ } \\
\text { m/v "Lirica" }\end{array}$ & 1 & 1 & - & - & - & 6 & 5 & 7 \\
\hline $\begin{array}{c}\text { Towed train/ } \\
\text { "Wagenborg Barge 4", } \\
\text { m/t "Java Victor" }\end{array}$ & 1 & 2 & - & - & - & 5 & 6 & 6 \\
\hline
\end{tabular}

\subsubsection{Scenario 1. Container Ship}

The simulation test scenario assumed that experts would perform a series of simulation passages consisting of safe berthing of the container ship Green Breeze, port side alongside Hutników Quay in the port of Świnoujście (Figure 3).

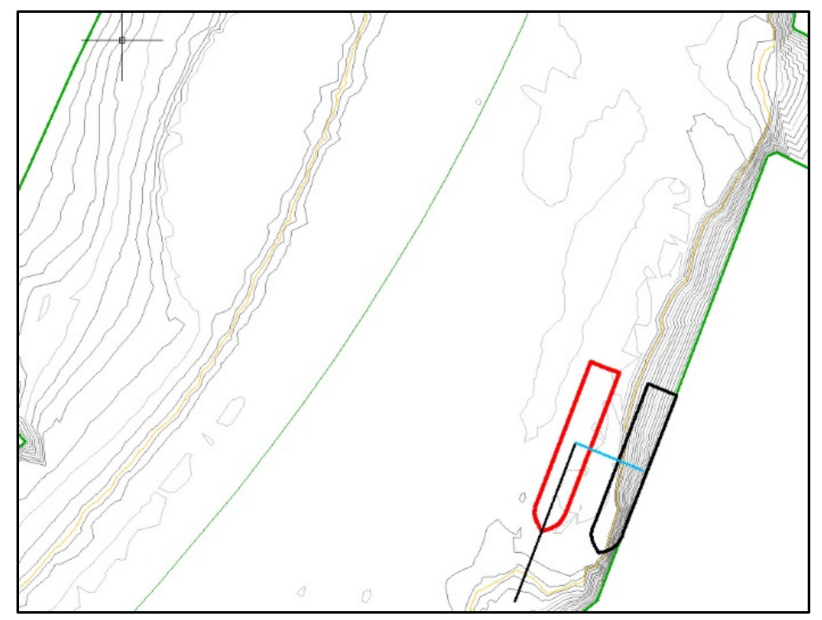

Figure 3. The situational-navigational plan of Scenario 1 for container ship passages. Red-initial position, black-destination.

The maximum contour of the ship presented in the Pilot_max system overlapped with the collision contour presented in the Pilot_precise system. Therefore, simulation passages were conducted for one system, assumed to be more accurate, i.e., Pilot_precise.

The detailed assumptions of Scenario 1 were as follows:

- Objective to be achieved: The lowest resultant value of the speed at the moment of contact of the ship's hull with the fender while achieving the shortest possible maneuver time.

- Main ship parameters:

○ $\quad$ LOA $=121.4 \mathrm{~m}$, breadth $=20.8 \mathrm{~m}$, draught $=6.88 \mathrm{~m}$;

○ Displacement $=11,250 \mathrm{t}$;

- $\quad$ Block coefficient $=0.709$;

$\circ \quad$ Main engine: $1 \times$ diesel, total power $=4000 \mathrm{~kW}$;

- $\quad$ Max speed $=14.2 \mathrm{kn}$;

- Type of propulsion: $1 \times \mathrm{fpp}$, clockwise;

$\circ \quad$ Number of rudders: 1 ;

- $\quad$ Max rudder angle $=35.0$ deg.;

- Number of thrusters: 1 ; 
○ $\quad$ Bow thruster power $=360 \mathrm{~kW}$.

- Navigational-maneuvering conditions:

- The initial position of the ship: parallel to berth, distance- - two ship's breadths from Hutników Quay;

- $\quad$ ship's final position: Hutników Quay;

- initial SOG: longitudinal $\mathrm{vw}=0.0 \mathrm{kn}$, transverse to port side $\mathrm{vp}=0.5 \mathrm{kn}$;

$\circ$ heading: $\mathrm{HDG}=200^{\circ}$.

- The criteria used for assessment:

- Primary: value of the resultant speed of the ship determined at the moment of contact with a fender;

- Secondary: efficiency of maneuvering-time length of maneuvers.

- The moment of measuring significant parameters: contact of the hull of the ship with a fender.

The types of displays used, the name of the series and the number of trials in a given series of the Scenario 1 are presented in the Table 2.

Table 2. Display types and number of trials for the container ship scenario.

\begin{tabular}{ccc}
\hline Displays & Series & Number of Trials \\
\hline Visual display & 1_Visual & 20 \\
ECDIS & 1_ECDIS & 20 \\
Pilot_precise & 1_Pprecise & 20 \\
AV & 1_AV & 20 \\
\hline
\end{tabular}

\subsubsection{Scenario 2. General Cargo Ship}

The simulation test scenario assumed that experts would perform a series of simulation trials consisting of safe berthing at an angle to the shore of the general cargo ship Arklow River, using a spring line, to Chemików Quay in the port of Świnoujście (Figure 4).

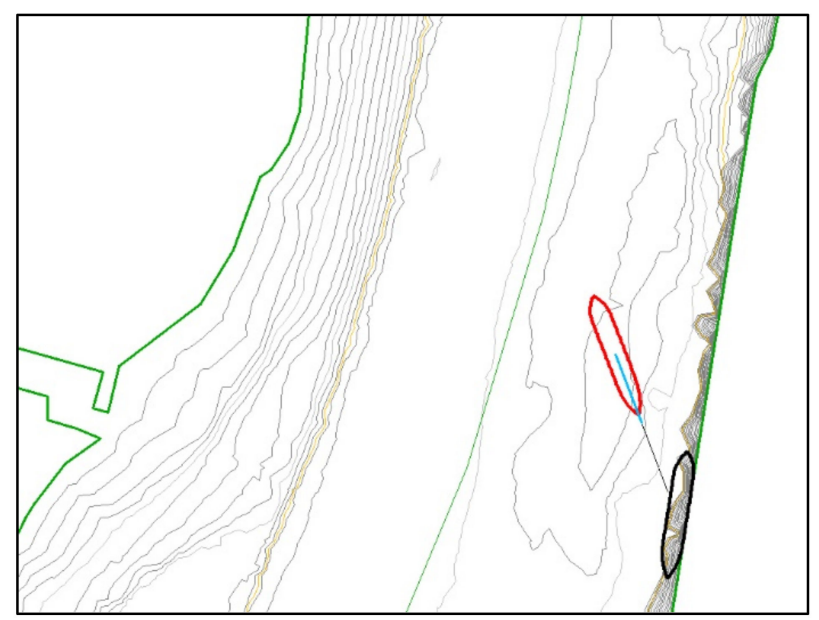

Figure 4. The situational-navigational plan of Scenario 2 for general cargo ship berthing. Red-initial position, black-destination.

The detailed assumptions of Scenario 2 were as follows:

- Objective to be achieved: The lowest resultant value of the speed at the moment of contact of the ship's hull with the fender while achieving the shortest possible maneuver time.

- Main ship parameters:

- $\quad$ LOA $=90 \mathrm{~m}$, breadth $=14 \mathrm{~m}$, draught $=5.7 \mathrm{~m}$;

○ $\quad$ Displacement $=5906 \mathrm{t}$; 
Block coefficient $=0.853$;

Main engine: $1 \times$ diesel, total power $=1499 \mathrm{~kW}$;

Max speed $=12 \mathrm{kn}$;

Type of propulsion: $1 \times$ cpp, counter-clockwise;

Number of rudders: 1 ;

Max rudder angle $=45.0$ deg.;

Number of thrusters: 1 ;

Bow thruster power $=250 \mathrm{~kW}$.

- Navigational-maneuvering conditions:

- the initial position of the ship: $30^{\circ}$ angle, distance of one length and two breadths of the ship from Chemików Quay;

- the ship's final position: Chemików Quay;

- initial SOG: longitudinal forward $\mathrm{v}_{\mathrm{w}}=0.5 \mathrm{kn}$, transverse $\mathrm{v}_{\mathrm{p}}=0.0 \mathrm{kn}$;

$\circ \quad$ heading: $\mathrm{HDG}=159^{\circ}$.

- $\quad$ The criteria used for assessment:

- Primary: the value of the resultant speed of the ship determined at the moment of contact with a fender;

- Secondary: efficiency of maneuvering - time length of maneuvers.

- The moment of measuring significant parameters: contact of the hull of the ship with a fender.

The types of displays used, the name of the series and the number of trials in a given series of the Scenario 2 are presented in the Table 3.

Table 3. Display types and number of trials for the general cargo ship scenario.

\begin{tabular}{ccc}
\hline Displays & Series & Number of Trials \\
\hline Visual display & 2_Visual & 20 \\
ECDIS & 2_ECDIS & 20 \\
Pilot_max & 2_Pmax & 20 \\
Pilot_precise & 2_Pprecise & 20 \\
AV & 2_AV & 20 \\
\hline
\end{tabular}

\subsubsection{Scenario 3. Sea Ferry}

The simulation test scenario assumed that experts would perform a series of simulation passages consisting of safe bow-to-berthing of the sea ferry Skania to the Ferry Terminal in Świnoujście (Figure 5). The mooring should have been such that the bow door of the ship could be opened, and the loading ramp could be connected.

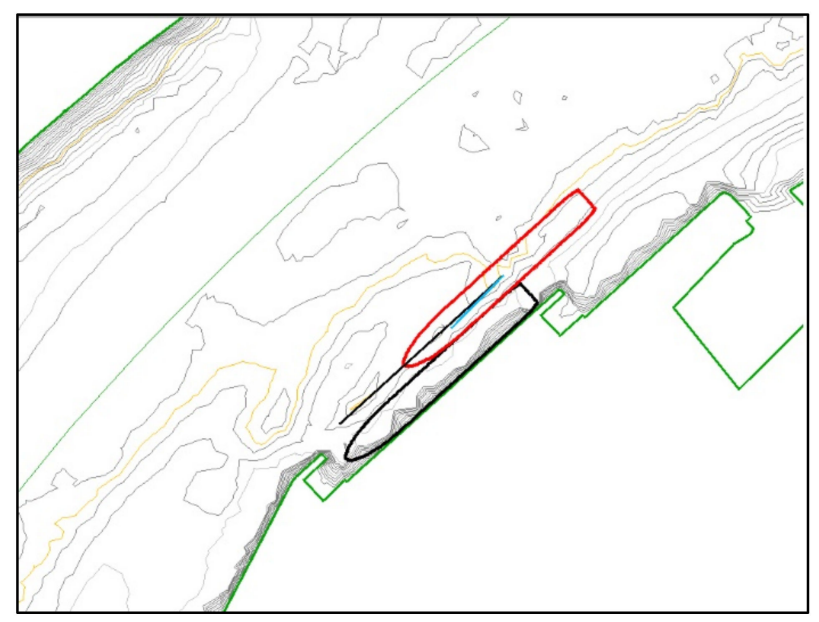

Figure 5. The situational-navigational plan of Scenario 3 for sea ferry berthing. Red-initial position, black-destination. 
It was assumed that the reference point lies in the line of the Ferry Terminal berth edge, on the symmetry plane of the discharge ramp, $10 \mathrm{~m}$ from the ramp. The moment of measuring the significant parameters took place at the moment when the navigator decided that he had reached the shortest distance from the reference point assumed in the study.

The detailed assumptions of Scenario 3 were as follows:

- $\quad$ Objective to be achieved: The lowest possible value of the ship distance from the theoretical point determining the ship's bow position in which the bow ramp can be effectively connected to the shore.

- Main ship parameters:

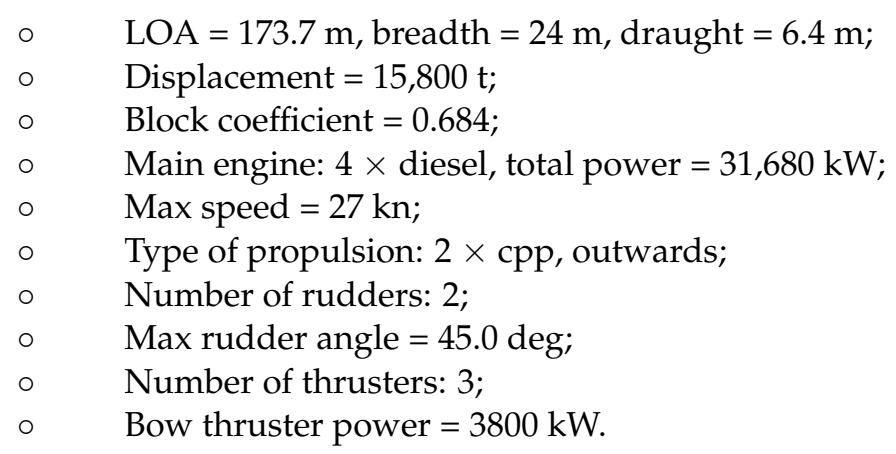

- Navigational-maneuvering conditions:

- the initial position of the ship: parallel, distance half the ship's length from the ramp and two ship's breadths from the Ferry Terminal Quay;

- the ship's final position: Ferry Terminal Quay;

- initial SOG: longitudinal ahead $\mathrm{v}_{\mathrm{w}}=0.5 \mathrm{kn}$, transverse to port side $\mathrm{v}_{\mathrm{p}}=0.1 \mathrm{kn}$;

$\circ \quad$ heading: $\mathrm{HDG}=227^{\circ}$.

- The criteria used for assessment:

- Primary: the value of the minimum distance of ship's hull from the navigational obstruction (assumed reference point);

- Secondary: efficiency of maneuvering-time length of maneuvers.

- The moment of measuring significant parameters: on the explicit command of the navigator, when the navigator considers that the ship has reached the lowest distance to the assumed reference point.

The types of displays used, the name of the series and the number of trials in a given series of the Scenario 3 are presented in the Table 4.

Table 4. Display types and number of trials for the sea ferry scenario.

\begin{tabular}{ccc}
\hline Displays & Series & Number of Trials \\
\hline Visual display & 3_Visual & 12 \\
ECDIS & 3_ECDIS & 12 \\
Pilot_max & 3_Pmax & 12 \\
Pilot_precise & 3_Pprecise & 12 \\
AV & 3_AV & 12 \\
\hline
\end{tabular}

\subsubsection{Scenario 4. Cruise Ship}

The simulation test scenario assumed that experts would perform a series of simulation trials consisting of the safe passage of the cruise ship Lirica along the determined section of the Świnoujście-Szczecin fairway. The ship passage consisted of the withdrawal of the ship from Kanał Grabowski to Przesmyk Orli turning basin, starboard turn and entry into a straight fairway section called Przekop Mieleński, towards the port of Świnoujście (Figure 6). 


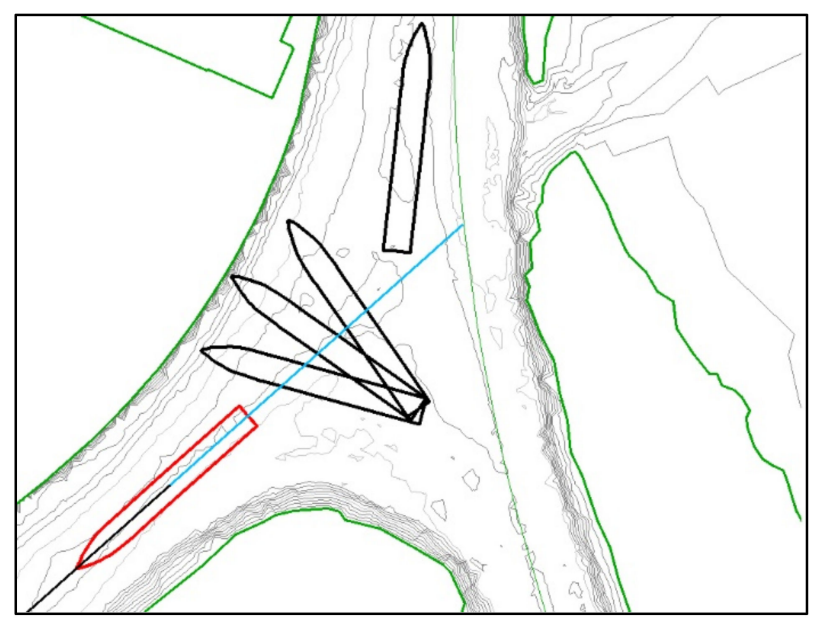

Figure 6. The situational-navigational plan of Scenario 4 for cruise ship passage. Red-initial position, black-destination.

During the experiment, the navigator was required to achieve the lowest possible value of the distance from the ship's hull to the east shore of Gryfia Island. The maneuver was necessary to keep the ship's stern away from Wielka Kempa island as adjacent waters are not navigable.

The detailed assumptions of Scenario 4 were as follows:

- Objective to be achieved: the lowest possible value of the distance from the ship's hull to the east shore of Gryfia Island.

- Main ship parameters:

- $\quad$ LOA $=251.25 \mathrm{~m}$, breadth $=28.8 \mathrm{~m}$, draught $=6.84 \mathrm{~m}$;

$\circ \quad$ Displacement $=59,058 \mathrm{t}$;

○ $\quad$ Block coefficient $=0.649$;

○ $\quad$ Main engine: $4 \times$ diesel, total power $=31,500 \mathrm{~kW}$;

○ $\quad$ Max speed $=22.5 \mathrm{kn}$;

- Type of propulsion: $2 \times$ cpp, outwards;

- Number of rudders: 2;

$\circ \quad$ Max rudder angle $=45.0 \mathrm{deg}$;

- Number of thrusters: 4;

- Bow thruster power $=4200 \mathrm{~kW}$;

○ Stern thruster power $=2800 \mathrm{~kW}$.

- Navigational-maneuvering conditions:

- the initial position of the ship: Kanał Grabowski, next to Przesmyk Orli turning basin;

- the ship's final position: Przekop Mieleński, as far as Trymerski Basin towards Świnoujście;

$\circ \quad$ initial SOG: longitudinal astern $\mathrm{v}_{\mathrm{w}}=4.0 \mathrm{kn}$, transverse $\mathrm{v}_{\mathrm{p}}=0.0 \mathrm{kn}$;

$\circ \quad$ heading: $\mathrm{HDG}=228^{\circ}$.

- The criteria used for assessment:

- Primary: the value of the minimum distance of ship's hull from the navigational obstruction (east shore of Gryfia Island);

- Secondary: efficiency of maneuvering-time length of maneuvers.

- The moment of measuring significant parameters: after the passage ends, the least recorded value of the cruise ship distance from the east shore of Gryfia Island, determined from a single passage.

The types of displays used, the name of the series and the number of trials in a given series of the Scenario 4 are presented in the Table 5. 
Table 5. Display types and number of trials for the cruise ship scenario.

\begin{tabular}{ccc}
\hline Displays & Series & Number of Trials \\
\hline Visual display & 4_Visual & 20 \\
ECDIS & 4_ECDIS & 20 \\
Pilot_max & 4_Pmax & 20 \\
Pilot_precise & 4_Pprecise & 20 \\
AV & 4_AV & 20 \\
\hline
\end{tabular}

\subsubsection{Scenario 5a. Tow Train-Unberthing}

The simulation test Scenario 5a included the experts' simulated series of passages consisting of safe unberthing of the sea barge Wagenborg 4 from Jachtowe Quay, using two tugs Java Victor, connected with the barge by towing lines. The passage consisted of unberthing and towing the sea barge possibly close to the Świnoujście-Szczecin fairway center line, then directing the tug-barge train to proceed along a straight stretch of the Odra Zachodnia river, towards the port of Świnoujście (Figure 7).

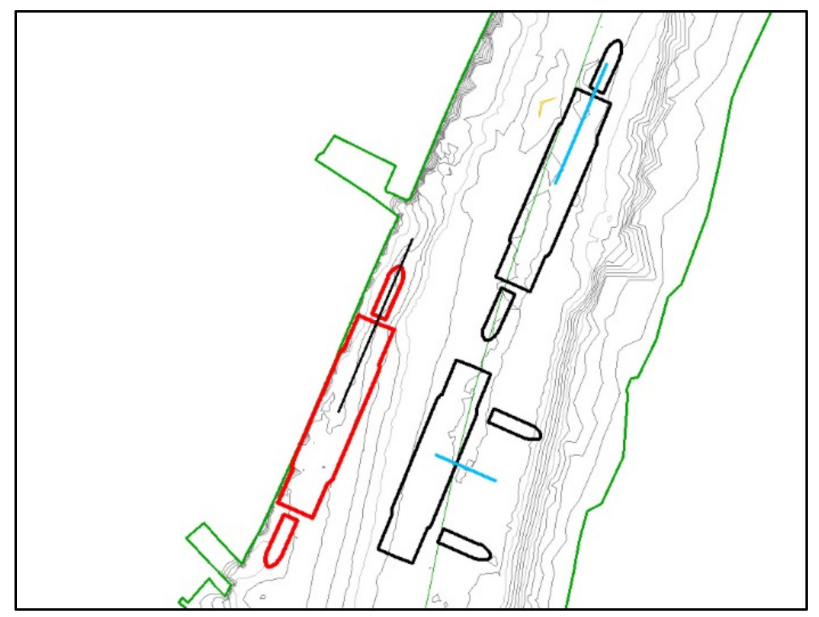

Figure 7. The situational-navigational plan of Scenario 5a for tow train unberthing. Red-initial position, black-destination.

The detailed assumptions of Scenario 5a were as follows:

- Objective to be achieved: the lowest possible value of the maneuvering area width, determined by the barge's contour and the two towing vessels.

- Main tow train parameters:

- Barge LOA $=100 \mathrm{~m}$, breadth $=33 \mathrm{~m}$, draught $=6.05 \mathrm{~m}$;

- Tug LOA $=41.8 \mathrm{~m}$, breadth $=11.4 \mathrm{~m}$, draught $=4 \mathrm{~m}$;

- Displacement $=1036 \mathrm{t}$;

○ $\quad$ Block coefficient $=0.555$;

- Main engine: $2 \times$ diesel, total power $=2939 \mathrm{~kW}$;

- $\quad$ Max speed $=13.6 \mathrm{kn}$;

- Type of propulsion: $2 \times \mathrm{fpp}$, outwards;

- Number of rudders: 2;

- $\quad$ Max rudder angle $=45.0 \mathrm{deg}$.

- Navigational-maneuvering conditions:

- the initial position of the tow: parallel to Jachtowe Quay;

$\circ \quad$ the final position of the tow: the center line of Szczecin-Świnoujście fairway northward;

- initial SOG: longitudinal $\mathrm{v}_{\mathrm{w}}=0.0 \mathrm{kn}$, transverse $\mathrm{v}_{\mathrm{p}}=0.0 \mathrm{kn}$;

$\circ$ heading: $\mathrm{HDG}=025^{\circ}$.

- The criteria used for assessment: 
Primary: the value of the average and maximum maneuvering area of the tow train, determined from maximum distances of the tow train's contour from the assumed reference point;

- Secondary: efficiency of maneuvering - time length of maneuvers.

- The moment of measuring significant parameters: maximum distances of the tow train's contour from the adopted reference point, calculated analytically after the passage was completed on the basis of registered coordinates of the center of gravity of the barge and tugs.

The types of displays used, the name of the series and the number of trials in a given series of the Scenario 5a are presented in the Table 6.

Table 6. Display types and number of trials for the tow train unberthing.

\begin{tabular}{ccc}
\hline Displays & Series & Number of Trials \\
\hline Pilot_precise & 5a_Pprecise & 12 \\
AV & 5a_AV & 12 \\
\hline
\end{tabular}

\subsubsection{Scenario 5b. Two Train-Turning}

The simulation test Scenario $5 \mathrm{~b}$ included the experts' simulated series of passages consisting of a safe turning of the sea barge Wagenborg 4 from Jachtowe Quay, using two tugs Java Victor, connected with the barge by towing lines.

The passage consisted in towing the sea barge from Dock No 5 to a turning basin on the Odra Zachodnia river, opposite Cal Quay, then turning the barge around its starboard side and passage of the tow train along the straight section of Przekop MIeleński canal (Figure 8).

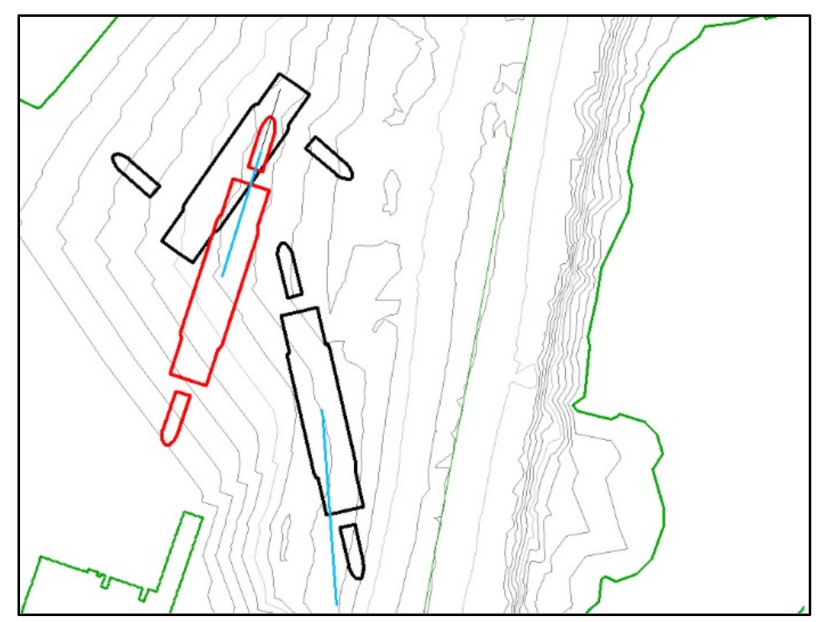

Figure 8. The situational-navigational plan of Scenario 5b for tow train turning. Red-initial position, black-destination.

- The detailed assumptions of Scenario $5 \mathrm{~b}$ were as follows:

- Objective to be achieved: same as in Scenario 5a.

- Main ship parameters: same as in Scenario 5a.

- Navigational-maneuvering conditions:

- the initial position of the tow: parallel to Jachtowe Quay;

- the final position of the tow: the center line of Szczecin-Świnoujście fairway northward;

- initial SOG: longitudinal $\mathrm{v}_{\mathrm{w}}=0.0 \mathrm{kn}$, transverse $\mathrm{v}_{\mathrm{p}}=0.0 \mathrm{kn}$;

$\circ$ heading: $\mathrm{HDG}=025^{\circ}$.

- The criteria used for assessment: same as in Scenario 5a.

- The moment of measuring significant parameters: same as in Scenario 5a. 
The types of displays used, the name of the series and the number of trials in a given series of the Scenario $5 \mathrm{~b}$ are presented in the Table 7.

Table 7. Display types and number of trials for the tow train turning.

\begin{tabular}{ccc}
\hline Displays & Series & Number of Trials \\
\hline Pilot_precise & 5b_Pprecise & 12 \\
AV & 5b_AV & 12 \\
\hline
\end{tabular}

\subsection{Data Recording and Analysis}

Scenario 5a,b included two variants of the passages using the display of the SDSS, defined as the most precise in Scenarios 1-4. Based on the test results analysis referring to the previous scenarios, the variants of passages using the displays as indicated in Tables 6 and 7.

In the simulation passages for the tow train variant, it was impossible to use visual display due to hardware limitations of the simulated movement model (technological solutions used on the simulator bridge). The limitation consisted in the need to use a peripheral device, such as a joystick, to change the navigator's field of vision. Taking into account the limitations in the visual observation field to $30^{\circ}$ (small bridge option), the necessity of frequent change in the observation point made the effective control of the tug impossible.

Commonly known empirical methods were used to calculate the maneuvering area of the vessels [47].

The detailed conditions of the simulation study for all scenarios are as follows:

1. Hydro-meteorological conditions:

a. wind speed and direction: no wind;

b. $\quad$ speed and direction of the current: output current $\mathrm{v}_{\mathrm{c}}=0.0 \mathrm{kn}$ up to $0.1 \mathrm{kn}$;

c. visibility: good;

d. time of day: day;

e. waves: no waves;

f. the effects implemented in the model: ship-shore and squat.

2. Automatic registration of significant parameters (random variables) in the simulation model of ship movement and the model of the visualization method in AV technology in the interval of $2 \mathrm{~s}$.

\subsection{General Assumptions of the Simulation Study}

The general assumptions of the simulation study for all the scenarios were as follows:

1. Where it was considered appropriate, a series of simulation passages in specific scenarios were conducted for all four graphic SDSS and visual observation.

2. Each series of simulation passages was conducted separately for each of the selected SDSSs, i.e., at the moment of using a given system, all the systems under consideration in the testing were excluded (not applicable to visual observation). This was intended to increase the probability that during maneuvering, the navigator does not use information from another system, which could falsify the results.

3. The series of passages were not fewer than the specified minimum number of simulation tests for a given test scenario.

4. All the systems used were provided with the same input data necessary for their correct operation, i.e., standardized NMEA data.

5. Each passage was preceded by one trial passage, and the navigator could read the ship's documentation to familiarize himself with the maneuvering characteristics.

6. The passages that did not meet the assumed criteria were not accepted for analysis. A passage was considered invalid if: 
a. the ship had contact with the shore, bottom or surface object, as a result of which critical values of acceleration forces determined in the simulation model of ship movement were exceeded,

b. maneuvers significantly differed from assumptions defined by the author in the scenario.

\section{Results}

The herein presented statistical analysis of recorded simulation passage data consisted of the verification of the hypotheses on the normality of random variables distribution (Table 8):

1. resultant speed $V_{1}$ of the container ship determined at the moment of contact with the fender and time $T_{1}$ of maneuver performance, obtained for four variants of Scenario 1;

2. resultant speed $V_{2}$ of the general cargo ship determined at the moment of contact with the fender and time $T_{2}$ of maneuver performance, obtained for four variants of Scenario 2;

3. the distances of the sea ferry from the assumed point of reference $X_{3}$ obtained for five variants of Scenario 3;

4. the distances $X_{4}$ of the cruise ship from the east shore of Gryfia Island obtained for five variants of Scenario 4;

5. the distances of the tow train contour points from the assumed reference point $D_{5 \mathrm{a}}$ obtained for two variants of Scenario $5 a$ and $D_{5 b}$ obtained for two variants of Scenario $5 b$;

and the comparison of the mean, variance and multiple comparisons of the means. Depending on the number of variants in simulation scenarios (number of independent groups), the statistical inference was conducted as presented below.

Table 8. The list of random variables subjected to statistical analysis based on the scenario variant.

\begin{tabular}{|c|c|c|c|c|c|}
\hline 1 & 2 & 3 & 4 & 5 & 6 \\
\hline Scenario & Variant of the Scenario & $\begin{array}{c}\text { Random Variable of the Primary } \\
\text { Criterion }\end{array}$ & $\begin{array}{l}\text { Independent Groups of } \\
\text { the Random Variable of } \\
\text { the Primary Criterion }\end{array}$ & $\begin{array}{l}\text { Random Variable of the } \\
\text { Secondary Criterion }\end{array}$ & $\begin{array}{l}\text { Independent Groups of } \\
\text { the Random Variable of } \\
\text { the Secondary Criterion T }\end{array}$ \\
\hline \multirow{4}{*}{1} & 1_Visual & \multirow{4}{*}{$\begin{array}{l}\text { V1-resultant speed of the } \\
\text { container ship determined at the } \\
\text { moment of contact with the fender } \\
(\mathrm{kn})\end{array}$} & V1_Visual & \multirow{4}{*}{$\begin{array}{l}\mathrm{T} 1 \text { - time of maneuver } \\
\text { performance }(\mathrm{s})\end{array}$} & T1_Visual \\
\hline & 1_ECDIS & & V1_ECDIS & & T1_ECDIS \\
\hline & 1_Pprecise & & V1_Pprecise & & T1_Pprecise \\
\hline & 1_AV & & V1_AV & & T1_AV \\
\hline \multirow{5}{*}{2} & 2_Visual & \multirow{5}{*}{$\begin{array}{l}\text { V2-resultant speed of the general } \\
\text { cargo ship determined at the } \\
\text { moment of contact with the fender } \\
(\mathrm{kn})\end{array}$} & V2_Visual & \multirow{5}{*}{$\begin{array}{l}\mathrm{T} 2 \text { - time of maneuver } \\
\text { performance }(\mathrm{s})\end{array}$} & T2_Visual \\
\hline & 2_ECDIS & & V2_ECDIS & & T2_ECDIS \\
\hline & 2_Pmax & & V2_Pmax & & T2_Pmax \\
\hline & 2_Pprecise & & V2_Pprecise & & T2_Pprecise \\
\hline & 2_AV & & V2_AV & & T2_AV \\
\hline \multirow{5}{*}{3} & 3_Visual & \multirow{5}{*}{$\begin{array}{l}\mathrm{X} 3 \text { - distance of the sea ferry from } \\
\text { the assumed point of reference }(\mathrm{m})\end{array}$} & X3_Visual & & \\
\hline & 3_ECDIS & & X3_ECDIS & & \\
\hline & 3_Pmax & & X3_Pmax & & \\
\hline & 3_Pprecise & & X3_Pprecise & & \\
\hline & 3_AV & & X3_AV & & \\
\hline \multirow{5}{*}{4} & 4_Visual & \multirow{5}{*}{$\begin{array}{l}\text { X4-distance of the cruise ship from } \\
\text { the east shore of Gryfia Island }(\mathrm{m})\end{array}$} & X4_Visual & & \\
\hline & 4_ECDIS & & X4_ECDIS & & \\
\hline & 4_Pmax & & X4_Pmax & & \\
\hline & 4_Pprecise & & X4_Pprecise & & \\
\hline & 4_AV & & X4_AV & & \\
\hline \multirow{2}{*}{$5 a$} & 5a_Pprecise & \multirow{2}{*}{$\begin{array}{l}\text { D5a-distance of the tow train } \\
\text { contour points from the assumed } \\
\text { reference point }(\mathrm{m})\end{array}$} & D5a_Pprecise & & \\
\hline & 5a_AV & & D5a_AV & & \\
\hline \multirow{2}{*}{$5 b$} & 5b_Pprecise & \multirow{2}{*}{$\begin{array}{l}\mathrm{D} 5 \mathrm{~b} \text { - distance of the tow train } \\
\text { contour points from the assumed } \\
\text { reference point }(\mathrm{m})\end{array}$} & D5b_Pprecise & & \\
\hline & 5b_AV & & D5b_AV & & \\
\hline
\end{tabular}


For the scenario of unberthing (5a) and turning (5b) of the tow train, where statistical analysis was applied to $k=2$ independent groups of the random variable of the distance of the tow train contour points from the adopted reference point, the equality of the means was verified by the parametric test. The specific hypotheses were adopted:

Hypothesis $\mathbf{0}(\mathbf{H 0 )}$. The mean distances of the tow train contour from the reference point assumed for the tests using a specific navigator's decision support system and the system in the augmented virtuality method are equal $m_{b}=m_{A V}$.

Hypothesis 1 (H1). The mean distances of the tow train contour points from the reference point assumed for the tests using a specific navigator's decision support system and the system in the augmented virtuality method are different $m_{b} \neq m_{A V}$.

Depending on the outcome of the test on the homogeneity of the variance of the distribution of the random variable distance of the tow train contour from the assumed reference point in the independent groups of Scenarios $5 \mathrm{a}, \mathrm{b}$, two variants of the significance test of the mean differences were used:

- $\quad$ Student's $t$-test in the case where the variances were homogeneous;

- transformation of $t$-test-the Cochran-Cox test for heterogeneous variances.

For the simulation test Scenarios 1-4, where each statistical analysis was conducted for more than $k>2$ independent groups (Table 8) of the random variables of the primary criterion $V_{1}, V_{2}, X_{3}, X_{4}$, the equality of the means in the groups of the given simulation experiment scenario was verified by the parametric test. The specific hypotheses were adopted:

Hypothesis $\mathbf{0}(\mathbf{H 0 )}$. The means of random variable distribution in all independent groups for the tests using the decision support systems defined in the assumptions of a given simulation experiment scenario are equal, $m_{1}=m_{2}=m_{3}=m k$.

Hypothesis 1 (H1). At least two means of random variables distributions in independent groups for tests using the decision support systems defined in the assumptions of the given simulation experiment are different.

Depending on the outcome the homogeneity test of random variables distribution variances $V_{1}, V_{2}, X_{3}, X_{4}$, in independent groups (Table 8) of Scenarios 1-4, two variants of the significance test of the mean differences were applied:

- $\quad$ one-factor ANOVA analysis of the variance for independent tests, when the variances were homogeneous;

- Welsh test and Brown-Forsyth test for heterogeneous variances.

In the case of heterogeneous variances, the non-parametric Kruskal-Wallis test was excluded as the distributions of the analyzed random variables in independent groups were close to the normal distribution of the same size, their distributions were not similar, and the test is of lower power than parametric tests.

For the simulation test Scenarios 1-4, where each statistical analysis was conducted for more than 2 independent groups $(k>2)$ of the primary criterion $V_{1}, V_{2}, X_{3}, X_{4}$, and the outcome of the analysis of the mean equality was statistically significant, multiple comparisons between the groups analyzed were conducted using post hoc tests.

Depending on the outcome of the test for the homogeneous degree of variance, two variants of the multiple comparisons were applied:

- Tukey HSD test, where the variances were homogeneous;

- Games-Howell test for heterogeneous variances.

The adopted level of significance of the tests was $\alpha=0.05$. 
When the significance tests revealed no statistically significant differences between the means of the distributions of the random variables of the primary criterion $V_{1}, V_{2}, X_{3}$, $X_{4}, D_{5 a}, D_{5 \mathrm{~b}}$ in independent groups obtained in all the variants of the Scenarios $1-5 \mathrm{~b}$ or the multiple comparisons tests revealed no statistically significant differences between the means of distributions of the random variables of primary criterion $V_{1}, V_{2}, X_{3}, X_{4}, D_{5 a}$, $D_{5 \mathrm{~b}}$ in independent groups obtained in the variant passages using the AV system and the groups of the other passages in the Scenarios 1-5b, a statistical analysis of independent groups of random variables of the secondary criterion (the time of maneuvering) $T$ was conducted, where the inference process was similar to that described in this section.

The statistical analysis, discussed further in this section, of the random variables of primary criterion $V_{1}, V_{2}, X_{3}, X_{4}$, in the independent groups of Scenarios 1-4 showed that there was a need to carry out a similar inference for the random variable of the Secondary criterion, time of maneuvering $T$, in Scenarios 1 and 2. Therefore, the description of the statistical inference for the random variables of the primary criterion includes statistical analysis for the random variable of the secondary criterion in Scenarios 1 and 2.

\subsection{Verification of Hypotheses on the Normality of the Random Variable Distribution}

After the analysis of the values of the test statistics obtained from the performed tests of the normality of the distribution of random variables of the primary criterion, in the independent groups of Scenarios from 1 to $5 \mathrm{~b}$, there was no basis for the rejection of the hypotheses on the normality of the distribution of the tested random variables.

In all cases, the $W$ test statistics (Shapiro-Wilk test) of the random variables of the primary criterion, as well as the random variables of the secondary criterion in Scenario 1 (container ship berthing) and Scenario 2 (general cargo ship berthing) turned out insignificant $(p>0.05)$; therefore, the hypotheses on the normality of distribution was accepted.

\subsection{The Comparison of the Random Variables Obtained from the Series of Tests for All Variants of} Simulation Scenarios

The first stage of the analysis of the obtained results consisted in the comparison of the arithmetic means of distributions of all random variables: $V_{1}, T_{1}, V_{2}, T_{2}, X_{3}, X_{4}, D_{5 a}$, $D_{5 \mathrm{~b}}$ in independent groups (Table 8), obtained during all simulation passages of the ships.

It should be noted that for Scenarios 1 and 2, the measured parameter-resultant speed-has relatively small values, which may vary from the actual operational parameters of the given ship. This is due to the assumption that the simulation experiment requires the navigator to achieve the lowest possible value of resultant speed while performing the maneuver in the possibly shortest time. The assumption was aimed to eliminate the situation where the navigator would adopt a subjective, higher level of the resultant speed, that in his judgement would be safe for a given ship (depending on the navigator's habits). That, in some way, specified the reference level for the analyzed random variables. This is important for statistical analysis of the measurement results and enables the assessment of the usefulness of the system during maneuvering.

\subsection{The Comparison of the Random Variables of Scenario 1. Container Ship}

The values of the arithmetic mean of the distributions of the resultant container ship speed determined at the moment of container ship contact with the fender, during parallel berthing along the ship's port side, are similar for all variants of passage, except for the test series using the ECDIS system (Table 9). The value of the mean distribution of the random variable V1_ECDIS is on average larger by $20 \%$ than the other. 
Table 9. The comparison of the arithmetic mean of the distributions of the resultant ship speed and maneuvering times for the container ship.

\begin{tabular}{cccccc}
\hline & \multicolumn{5}{c}{$V_{1}$-Resultant Speed of the Container Ship Determined at the Moment of } \\
Contact with the Fender $\mathbf{( k n )}$
\end{tabular}

The analysis of the values of the arithmetic means of the distribution of the random variable of maneuvering time in independent groups for the container ship, like previously, showed a slight difference in the values, except the passages using the ECDIS system. The difference between the arithmetic mean of the distribution of the random variable T1_ECDIS obtained during passages using that system and the other was on average $15 \%$. No significant differences were observed in the mean distribution of the random variables of maneuvering times for the other series of simulation tests.

It should be noted that despite clear differences in the mean distribution of resultant speed and time length of performed maneuvers in independent groups for variants 1 _Visual, 1_Pprecise, 1_AV, for the latter two, the mean is slightly larger than for the variant with visual observation. This dependence occurs when we adopt the conditions of good visibility for visual observation. When restricted visibility is introduced, such a relationship may not occur.

The differences observed (at least one pair) in the values of the mean distribution of the random variables of resultant speed and maneuvering time in independent groups obtained for four variants of Scenario 1 gave the basis for further analysis, in which the means were compared at the confidence level 0.95 .

\subsection{The Comparison of the Random Variables of Scenario 2. General Cargo Ship}

The values of the arithmetic mean of the distribution of the resultant speed of the general cargo ship determined at the moment of contact with the fender, performing diagonal berthing along the port side, vary for all five passage variants (Table 10). The lowest value of the arithmetic mean of the distribution of the random variable speed $V_{2}$ and maneuvering time $T_{2}$ was observed for the 2_AV variant passage using the decision support system featuring the AV-based display method. The highest values of the mean distribution of resultant speed $V_{2}$ and maneuvering time $T_{2}$ were obtained for the passage variant 2_ECDIS.

Table 10. The comparison of the arithmetic mean of the distributions of the resultant ship speed and maneuvering times for the general cargo ship.

\begin{tabular}{cccccc}
\hline & \multicolumn{5}{c}{$V_{\mathbf{2}}$-Resultant Speed of the General Cargo Ship Determined at the Moment } \\
of Contact with the Fender (kn)
\end{tabular}

The difference between the largest and the smallest values of the mean distribution of resultant ship speed in independent groups, obtained for five variants of Scenario 2, is approximately $60 \%$ and close to $80 \%$ for maneuvering time. This relationship that was created on the basis for further analysis conducted similarly to that for the container ship passages in Scenario 1. 


\subsection{The Comparison of the Random Variables of Scenario 3. Sea Ferry and Scenario 4 Cruise Ship}

Similar to Scenario 2, in Scenarios 3 and 4, similar relationships were observed between the arithmetic mean of the distribution of the random variable of the ship's hull distance from the assumed reference point in the independent groups, obtained in all the variants of Scenario 3 for the sea ferry and all five variants of Scenario 4 for the cruise ship.

In Scenario 3, the difference between the largest value of the distribution of the random variable X3_ECDIS obtained in the variant 3_ECDIS (passages using the ECDIS system) and the smallest value of the mean distribution of the random variable X3_AV obtained in the variant 3_AV was more than nine-fold (Table 11).

Table 11. The comparison of the arithmetic means of the distribution of the random variable of the ship's hull distance from the assumed reference point for the sea ferry and cruise ship.

\begin{tabular}{cccccc}
\hline \multicolumn{5}{c}{$X_{3}$-Distance from Sea Ferry's Hull to the Assumed Reference Point (m) } \\
\hline Variant & 3_Visual & 3_ECDIS & 3_Pmax & 3_Pprecise & 3_AV \\
\hline $\begin{array}{c}\text { Scenario 3 } \\
\text { Sea ferry }\end{array}$ & 2.03 & 2.13 & 1.31 & 0.90 & 0.23 \\
\hline \multicolumn{7}{c}{ Variant } & 4_Visual & 4_ECDIS & 4_Pmax & 4_Pprecise & 4_AV \\
\hline $\begin{array}{c}\text { Scenario 4 } \\
\text { Cruise ship }\end{array}$ & 2.60 & 2.77 & 1.70 & 0.39 & 0.25 \\
\hline
\end{tabular}

In Scenario 4, the difference between the largest value of the mean distribution of the random variable X4_ECDIS obtained in variant 4_ECDIS and the smallest value of the mean distribution of the random variable $X 4 \_A V$ obtained in the variant 4_AV was over eleven-fold (Table 11).

It can be noted from the results that the value of the mean distribution of the random variable of the cruise ship distance from the east shore of Gryfia Island obtained for the passage variant 4_Pprecise (using the Pilot_precise system) is lower than for the sea ferry passage variant with the same system, while the values obtained for the other systems are in the inverse relationship. This is due to different moments of measuring the significant value for each variant. The shortest distance from the east quay of Gryfia Island during cruise ship turning was the lowest value of all recorded populations in the test sample. With a clearly specified reference in the form of the shoreline, the difficulty of the navigational task came down to get the ship's contour skillfully as close as possible during the turning maneuver.

In the case of the sea ferry berthing variant, the value of the lowest distance of the hull from the assumed (not visible) reference point was measured at the moment of the 'stop' command given by the navigator. The discretely monitored measurement of the distance using a marker was burdened with an error of marker setting and the absence of a clearly defined reference point. This situation did not refer to the AV system, and in the case of large inaccuracy in the estimation of distances using other systems and visual observation (place of the ship not visible from the bridge), it had a lower impact on the overall value.

The differences observed (at least one pair) in the values of the mean distribution of the random variable distance of the sea ferry from the assumed reference point in the independent groups, obtained for five variants of Scenario 3 and the mean distribution of the random variable of the cruise ship distance from the east shore of Gryfia Island in independent groups, obtained for five variants of Scenario 4, made the basis for further analysis, conducted similarly to the previous passages.

\subsection{The Comparison of the Random Variables of Scenarios $5 a$ and $5 b$. The Tow Train}

The values of the arithmetic mean of the distributions of the distances of the tow train contour from the assumed reference point for the passages variants 5a_Pprecise and 5a_AV in Scenario $5 a$ and for variants 5b_Pprecise and $5 b \_A V$ in Scenario $5 b$ differ significantly in the case of the mean and maximum areas. 
The mean and maximum areas determined for variant 5a_Pprecise (using the Pilot_precise system) of Scenario 5a (unberthing of the tow train) was on average more than $15 \%$ wider than the same areas obtained in the variants of passages 5a_AV (with the AV system) (Table 12).

Table 12. The comparison of the mean arithmetic distributions of the distances of the tow train contour points from the assumed reference point, for the mean and maximum maneuvering area, in two variants of scenario $5 \mathrm{a}$.

\begin{tabular}{|c|c|c|c|}
\hline \multicolumn{2}{|c|}{$\begin{array}{c}\text { Distance of the Tow Train Contour Points from } \\
\text { the Assumed Reference Point for the Mean } \\
\text { Maneuvering Area (m) }\end{array}$} & \multicolumn{2}{|c|}{$\begin{array}{c}\text { Distance of the Tow Train Contour Points from } \\
\text { the Assumed Reference Point for the } \\
\text { Maximum Maneuvering Area (m) }\end{array}$} \\
\hline Variant 5a_Pprecise & Variant 5a_AV & Variant 5a_Pprecise & Variant 5a_AV \\
\hline 131.31 & 114.72 & 138.16 & 119.03 \\
\hline
\end{tabular}

Similarly, the mean and maximum areas determined for variant 5b_Pprecise Scenario $5 \mathrm{~b}$ (turning of the tow train) were on average $16 \%$ wider than the same areas obtained in the variant of passages 5b_AV (Table 13).

Table 13. The comparison of the mean arithmetic distributions of the distances of the tow train contour points from the assumed reference point, for the mean and maximum maneuvering area, during the maneuver of turning.

\begin{tabular}{cccc}
\hline \multicolumn{2}{c}{ Mean Width of the Maneuvering Area $(\mathrm{m})$} & \multicolumn{2}{c}{ Maximum Width of the Maneuvering Area $(\mathrm{m})$} \\
\hline Variant 5b_Pprecise & Variant $5 \mathrm{~b} \_A V$ & Variant $5 \mathrm{~b} \_$Pprecise & Variant 5b_AV \\
\hline 103.76 & 89.34 & 116.52 & 99.77 \\
\hline
\end{tabular}

The comparison of the maneuvering areas of the tow train for unberthing and turning maneuvers are given in Figures 9 and 10.

The boundaries were determined according to the criteria of the mean area and the maximum area based on the assessment of the size and location of maneuvering areas calculated for simulation tests using the Pilot_precise system and AV.

The above relationships gave the basis for the further analysis conducted, similarly to the variants above, to check whether the differences observed in the first stage could be confirmed by a more detailed statistical analysis.

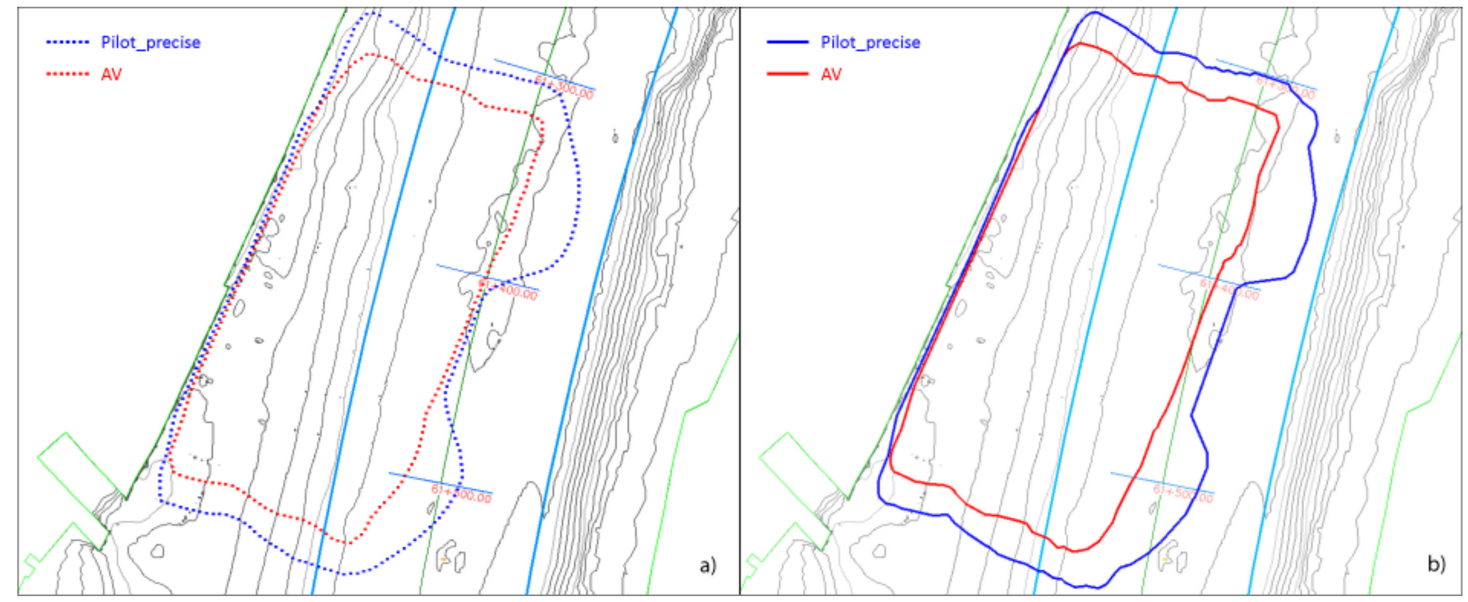

Figure 9. The maneuvering area for the variant of unberthing the tow train: (a) mean, (b) maximum. 


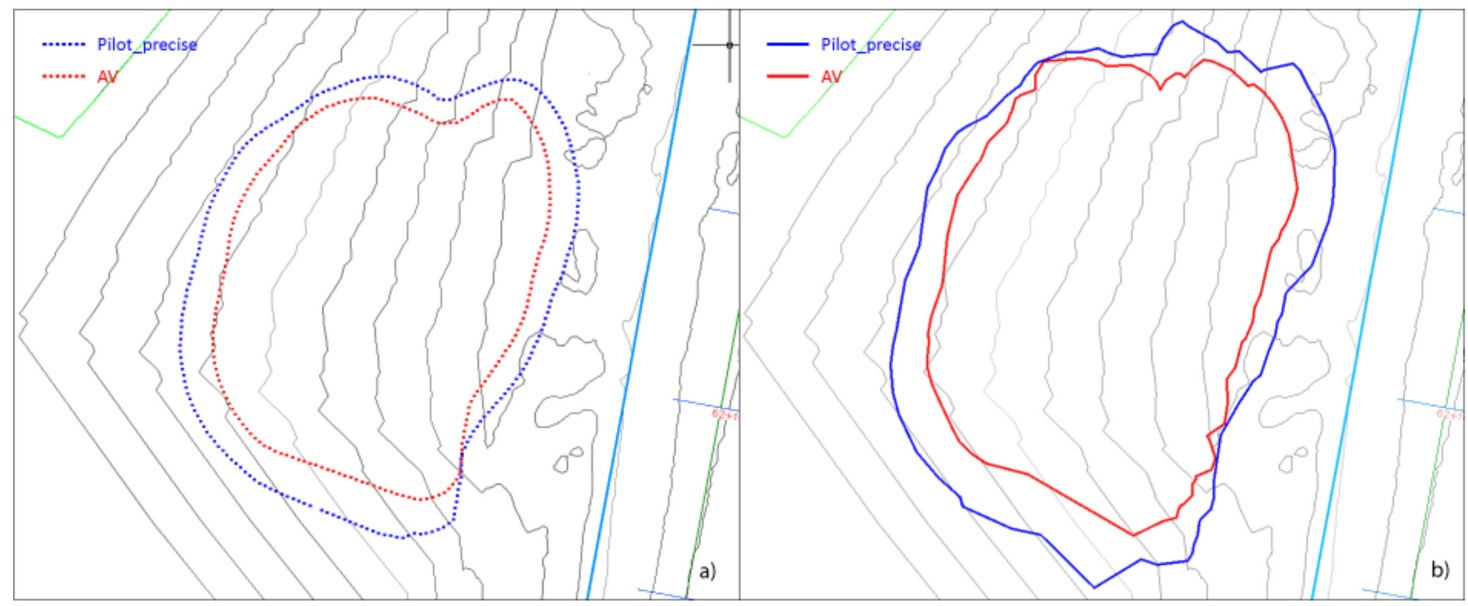

Figure 10. The maneuvering area for the variant of the tow train turning (a) mean, (b) maximum.

3.7. Statistical Tests of Differences between Random Variables Parameters Obtained from Series of Tests for All Variants of Simulation Scenarios

The initial analysis has shown differences in the mean distributions of all random variables in independent groups obtained in all the variants of simulation passages defined in the given experiment.

Therefore, it was decided to carry out statistical verification of the hypotheses on the equality of the means and variances for all the distributions of random variables (Table 8) in the independent groups obtained for all the simulated passage variants defined in Scenarios $1-5 b$.

To carry out statistical analysis for the random variable of the distance of the tow train contour points from the assumed reference point in the independent groups obtained for the variants of simulation passages:

- 5a_Pprecise and 5a_AV defined in Scenario 5a,

- 5b_Pprecise and 5b_AV defined in Scenario 5b,

the test population was reduced to the values obtained in 20 selected sectors of the mean and maximum maneuvering areas (Table 14).

To determine the homogeneity of the variances of the distributions of the random variables of primary criterion $V_{1}, V_{2}, X_{3}, X_{4}, D_{5 a}, D_{5 b}$ and secondary criterion $T_{1}, T_{2}$, (Table 8), in the independent groups obtained in all the simulation variants of the given Scenario s 1-5b, Levene tests and Brown-Forsyth tests were conducted.

The analysis of results indicated that in independent groups of random variables of the primary criterion $V_{1}, V_{2}, X_{3}, X_{4}$ and the secondary criterion $T_{1}, T_{2}$, obtained in all the simulation variants of the given Scenario 1-4, there are significant differences between the variances (the basis for the rejection of $\mathrm{H}_{0}$ at the significance level $\alpha=0.05$ ) for all the tests used.

For Scenarios 1-4, the level of the significance of the Leven test statistic and the Brown and Forsyth statistic assumed the values $p<0.05$. Therefore, it was concluded that the assumption on the homogeneity of the variances of the distributions of the random variables of the primary criterion $V_{1}, V_{2}, X_{3}, X_{4}$ and the secondary criterion $T_{1}$ and $T_{2}$ is not satisfied in the independent groups obtained in all the simulation variants of the given Scenario 1-4. This meant the need to use parametric tests for the independent groups with heterogeneous variances to determine the significance of the differences in the mean distributions of the random variables.

As the result of the analysis of all the independent groups of the random variables of the primary criterion, $D_{5 \mathrm{a}}$ and $D_{5 \mathrm{~b}}$, obtained in all the simulation variants of the given Scenario $5 a, b$, statistically significant differences were found between the variances (the basis for the rejection of the $\mathrm{H}_{0}$ on the defined level of significance $\alpha=0.05$ ) for all the tests used. 
Table 14. Distances of the tow train contour points from the reference point in 20 selected sectors of the mean and maximum maneuvering area scenarios $5 \mathrm{a}$ and $5 \mathrm{~b}$.

\begin{tabular}{|c|c|c|c|c|c|c|c|c|c|}
\hline & \multicolumn{2}{|c|}{ 5a_Pprecise } & \multicolumn{2}{|c|}{ 5a_AV } & \multicolumn{3}{|c|}{ 5b_Pprecise } & \multicolumn{2}{|c|}{ 5b_AV } \\
\hline & \multicolumn{4}{|c|}{$\begin{array}{l}\text { Distance of the Tow Train Contour Points } \\
\text { from the Assumed Reference Point of the } \\
\text { Maneuvering Area }(\mathrm{m})\end{array}$} & \multirow[b]{2}{*}{ Sector } & \multicolumn{4}{|c|}{$\begin{array}{c}\text { Distance of the Tow Train Contour Points } \\
\text { from the Assumed Reference Point of the } \\
\text { Maneuvering Area (m) }\end{array}$} \\
\hline Sector & Mean & Maximum & Mean & Maximum & & Mean & Maximum & Mean & Maximum \\
\hline 1 & 125.68 & 125.88 & 98.00 & 109.84 & 1 & 106.32 & 119.45 & 85.29 & 95.33 \\
\hline 4 & 125.06 & 125.53 & 110.06 & 111.09 & 5 & 108.62 & 124.28 & 88.08 & 94.89 \\
\hline 7 & 124.86 & 127.19 & 110.21 & 113.12 & 9 & 112.81 & 126.19 & 94.96 & 104.39 \\
\hline 10 & 134.87 & 137.14 & 120.56 & 122.30 & 10 & 113.34 & 126.80 & 96.75 & 105.60 \\
\hline 13 & 153.60 & 158.03 & 131.15 & 139.13 & 13 & 115.85 & 128.52 & 98.89 & 107.17 \\
\hline 16 & 154.94 & 168.02 & 141.39 & 147.82 & 19 & 117.45 & 126.89 & 100.26 & 106.97 \\
\hline 19 & 151.91 & 157.37 & 126.01 & 130.38 & 22 & 116.42 & 123.24 & 99.50 & 104.25 \\
\hline 22 & 146.10 & 152.49 & 114.61 & 121.95 & 25 & 114.28 & 118.69 & 97.52 & 101.61 \\
\hline 25 & 133.00 & 143.88 & 104.80 & 109.47 & 28 & 112.27 & 117.23 & 95.94 & 98.01 \\
\hline 28 & 102.80 & 115.62 & 100.39 & 104.68 & 31 & 111.92 & 114.69 & 96.51 & 100.23 \\
\hline 31 & 100.91 & 114.23 & 98.41 & 102.99 & 41 & 121.46 & 130.65 & 107.12 & 112.72 \\
\hline 34 & 101.35 & 115.46 & 98.57 & 104.17 & 55 & 124.15 & 135.41 & 110.30 & 130.37 \\
\hline 37 & 104.24 & 119.44 & 100.89 & 107.17 & 61 & 119.30 & 150.96 & 104.19 & 134.86 \\
\hline 40 & 128.12 & 143.50 & 104.96 & 111.91 & 72 & 119.60 & 141.25 & 102.30 & 115.75 \\
\hline 43 & 144.37 & 152.63 & 116.91 & 120.57 & 74 & 112.59 & 133.04 & 93.91 & 108.55 \\
\hline 46 & 149.91 & 158.11 & 125.85 & 131.53 & 78 & 96.57 & 113.92 & 76.73 & 80.98 \\
\hline 49 & 154.53 & 163.66 & 137.14 & 144.30 & 82 & 82.33 & 92.74 & 66.37 & 70.00 \\
\hline 52 & 148.99 & 151.79 & 128.98 & 133.04 & 96 & 64.51 & 70.78 & 51.60 & 58.44 \\
\hline 55 & 136.45 & 140.08 & 120.29 & 121.39 & 116 & 108.83 & 125.95 & 91.61 & 104.97 \\
\hline 58 & 123.26 & 127.14 & 109.77 & 114.17 & 120 & 110.71 & 131.06 & 88.71 & 105.86 \\
\hline
\end{tabular}

The analysis of the results of the Leven tests and Brown and Forsyth tests conducted for the independent groups of the distances of the tow train contour points from the assumed reference points $D_{5 \mathrm{a}}$ and $D_{5 \mathrm{~b}}$, obtained in all the simulation variants of the given Scenario $5 \mathrm{a}, \mathrm{b}$, showed that there are no statistically significant differences between the variances (there was no basis for the rejection of the $\mathrm{H} 0$ at the determined level of significance $\alpha=0.05$ ) for all the tests used.

For Scenario 5a,b, the level of significance of the Leven test statistic and Brown and Forsyth test statistic assumed the values $p>0.05$. Therefore, it was concluded that the assumption on the homogeneity of the variances of the distribution of the random variables of the primary criterion, i.e., the distances of the tow train contour points from the assumed reference point in the independent groups D5a_Pprecise and D5a_AV and independent groups D5b_Pprecise and D5b_AV of the mean and the maximum maneuvering areas is satisfied. This meant the need to use parametric tests for the independent groups with homogeneous variances to determine the significance of the differences in the mean distributions of the random variables.

To determine the significance of the mean differences for all variants of the simulation experiment scenarios, parametric tests were conducted. For Scenarios 1-4, in which each time a statistical analysis was conducted for more than two independent groups $(k>2)$ of the primary criterion, i.e.:

1. the resultant speed of the container ship determined at the moment of contact with the fender obtained for four variants of Scenario 1: V1_Visual, V1_ECDIS, V1_Pprecise, V1_AV; 
2. the resultant speed of the general cargo ship determined at the moment of contact with the fender obtained for five variants of Scenario 2: V2_Visual, V2_ECDIS, V2_Pmax, V2_Pprecise, V2_AV;

3. distances of the sea ferry from the assumed reference point obtained for five variants of Scenario 3: X3_Visual, X3_ECDIS, X3_Pmax, X3_Pprecise, X3_AV;

4. distances of the cruise ship from the east quay of Gryfia Island obtained for five variants of Scenario 4: X4_Visual, X4_ECDIS, X4_Pmax, X4_Pprecise, X4_AV;

and the random variables of the secondary criterion:

1. time of maneuvering obtained for four variants of Scenario 1: T1_Visual, T1_ECDIS, T1_Pprecise, T1_AV,

2. time of maneuvering obtained for five variants of Scenario 2: T2_Visual, T2_ECDIS, T2_Pmax, T2_Pprecise, T2_AV,

and at the same time, the variances were found to be heterogeneous in the above groups, and the equality of the mean distributions of the above random variables in the independent groups was verified by the Welsh test and the Brown and Forsyth test.

The results of Welsh tests and Brown and Forsyth tests showed no statistically significant differences between the mean distributions of the random variables of the container ship's speed $V_{1}$ determined at the moment of contact with the fender and the time of maneuvering $T_{1}$ in the independent groups obtained for all four simulation variants of Scenario 1.

The significance level of the test statistic for Scenario 1 assumed the value of $p>0.05$, which was the basis for accepting $\mathrm{H}_{0}$ at the set level of significance $\alpha=0.05$. There were no statistically significant differences between the mean distributions of the random variable $V_{1}$ in the independent groups V1_Visual, V1_ECDIS, V1_Pprecise, V1_AV and the random variable $T_{1}$ in the independent groups T1_Visual, T1_ECDIS, T1_Pprecise, T1_AV, which gave no basis for further thorough analysis-multiple comparisons-of the means using post hoc tests.

The results of the Welsh tests and Brown and Forsyth tests showed significant differences between the mean distributions of the random variables $V_{2}, T_{2}, X_{3}, X_{4}$ in $k>2$ independent groups obtained for all the simulation variants of Scenarios $2-4$.

The significance level of the test statistic for the given Scenario $2-4$ had a value $p<0.05$, which was the basis for rejecting $\mathrm{H}_{0}$ at the set level of significance $\alpha=0.05$.

The statistically significant differences between the mean distributions of the random variables were found:

3. V2 in the independent groups V2_Visual, V2_ECDIS, V2_Pmax, V2_Pprecise, V2_AV and T2 in the independent groups T1_Visual, T1_ECDIS, T2_Pmax, T1_Pprecise, T1_AV in Scenario 2 for the general cargo ship,

4. X3 in the independent groups X3_Visual, X3_ECDIS, X3_Pmax, X3_Pprecise, X3_AV in Scenario 3 for the sea ferry,

5. X4 in the independent groups X4_Visual, X4_ECDIS, X4_Pmax, X4_Pprecise, X4_AV in Scenario 4 for the cruise ship,

which created a basis for a further thorough analysis of the multiple comparisons of the means using post hoc tests.

Based on the Student's $t$-test, statistically significant differences were found between the mean distributions of the random variables of the tow train contour points from the assumed reference point $D_{5 \mathrm{a}}, D_{5 \mathrm{~b}}$, in the independent groups obtained for all the simulation variants of Scenarios $5 \mathrm{a}, \mathrm{b}$. Therefore, the $\mathrm{H}_{0}$ hypothesis was rejected at the determined level of significance $\alpha=0.05$ for all the groups examined by that test.

The significance level of the Student's $t$-test statistic assumed the values in the interval (0.000287;0.00182) for the mean and maximum maneuvering areas in Scenario 5a and $(0.00399 ; 0.000544)$ for the mean and maximum maneuvering areas in Scenario $5 \mathrm{~b}$. Therefore, it was ascertained that in all the variants, the assumption on the equality of the mean distributions of the random variables of the distances of the tow train contour points 
from the assumed reference point of the mean and the maximum maneuvering area was not satisfied.

\subsection{Analysis of Multiple Comparisons of the Means Using the Post Hoc Test}

To specifically determine significant differences between the mean distributions of the random variables $V_{2}, T_{2}, X_{3}, X_{4}$ in the independent groups obtained for all the simulation variants of a given Scenario $2-4$, the multiple comparison analysis was conducted. Rejecting the hypothesis $\mathrm{H}_{0}$ on the homogeneity of the variances $(p<0.05)$ in all the independent groups of Scenarios 2-4, where each time a statistical analysis was conducted for more than $k>2$ independent groups of the random variables $V_{2}, T_{2}, X_{3}, X_{4}$, the author used the Games-Howell test for heterogeneous variances.

\subsubsection{Multiple Comparison Analysis of the Parameters in Scenario 2. General Cargo Ship}

For the distributions of the random variable of the primary criterion, i.e., the resultant speed $V_{2}$ of the general cargo ship determined at the moment of contact with the fender in the independent group V2_AV obtained for variant 2_AV, the means differences turned out to be statistically significant for the level of significance $p<0.0001$, compared with the independent groups V2_Visual, V2_ECDIS, V2_Pmax, obtained for variants 2_Visual, 2_ECDIS and 2_Pmax, Scenario 2 (Table 15). That was a basis for rejecting the hypothesis $\mathrm{H}_{0}$ stating the equality of the means in the examined independent groups.

Table 15. The falsification of the hypotheses on the equality of mean distributions of random variables of general cargo ship resultant speed determined at the moment of contact with the fender and the time of maneuvering.

\begin{tabular}{|c|c|c|c|c|c|c|}
\hline \multicolumn{7}{|c|}{ Multiple Comparison for Variants of Scenario 2 (General Cargo Ship) } \\
\hline \multicolumn{7}{|c|}{ Games-Howell Test } \\
\hline \multirow{2}{*}{\multicolumn{2}{|c|}{ (I) Variant }} & \multirow{2}{*}{$\begin{array}{c}\text { Difference } \\
\text { Between the } \\
\text { Means (I-J) }\end{array}$} & \multirow[b]{2}{*}{$\begin{array}{l}\text { Standard } \\
\text { Error }\end{array}$} & \multirow[b]{2}{*}{ Significance } & \multicolumn{2}{|c|}{ 95\% Confidence Level } \\
\hline & & & & & $\begin{array}{l}\text { Lower } \\
\text { Limit }\end{array}$ & $\begin{array}{l}\text { Upper } \\
\text { Limit }\end{array}$ \\
\hline \multicolumn{2}{|c|}{ Dependent variable: } & \multicolumn{5}{|c|}{ Resultant speed [kn] } \\
\hline \multirow{4}{*}{ 2_AV } & 2_Visual & $-0.04650 *$ & 0.00654 & 0.000 & -0.0655 & -0.0275 \\
\hline & 2_ECDIS & $-0.05900 *$ & 0.00738 & 0.000 & -0.0806 & -0.0374 \\
\hline & 2_Pmax & -0.03700 * & 0.00505 & 0.000 & -0.0515 & -0.0225 \\
\hline & 2_Pprecise & -0.011 & 0.00395 & 0.061 & -0.0223 & 0.0003 \\
\hline \multicolumn{2}{|c|}{ Dependent variable: } & \multicolumn{5}{|c|}{ Time of maneuvering [s] } \\
\hline \multirow{4}{*}{ 2_AV } & 2_Visual & $-19.95000 *$ & 6.26749 & 0.025 & -38.0622 & -1.8378 \\
\hline & 2_ECDIS & $-49.75000 *$ & 6.73056 & 0.000 & -69.2681 & -30.2319 \\
\hline & 2_Pmax & -17.95000 & 7.75801 & 0.171 & -40.6005 & 4.7005 \\
\hline & 2_Pprecise & -3.95000 & 5.93095 & 0.962 & -21.0452 & 13.1452 \\
\hline
\end{tabular}

* green color-the difference between the means is significant at the level 0.05 .

No statistically significant differences were observed in the mean distributions of the random variable $V_{2}$ in the independent group $\mathrm{V} 2 \_\mathrm{AV}$ obtained for variant 2_AV, compared with the independent group V2_Pprecise obtained for variant 2_Pprecise. For the latter, there was a basis for accepting hypothesis $\mathrm{H}_{0}$.

For the distributions of the random variable of the secondary criterion, i.e., the time of maneuvering $T_{2}$ in the independent group T2_AV obtained for variant 2_AV, the differences turned out to be statistically significant for the level of significance having values $(p<0.0001 ; 0.025)$, compared with independent groups T2_Visual, T2_ECDIS, obtained for variants 2_Visual, 2_ECDIS, Scenario 2 (Table 15). Thus, there was a basis for rejecting the hypothesis $\mathrm{H}_{0}$ stating the equality of the means in the examined independent groups.

No statistically significant differences were observed in the mean distributions of the random variable $T_{2}$ in the independent group T2_AV obtained for variant 2_AV, com- 
pared with independent groups T2_Pmax, T2_Pprecise, obtained in variants 2_Pmax and 2_Pprecise. For the latter variants, there was a basis for accepting hypothesis $\mathrm{H}_{0}$.

\subsubsection{Analysis of Multiple Comparisons of the Parameters in Scenario 3. Sea Ferry}

For the distributions of the random variable of the primary criterion, the distance of the sea ferry from the assumed reference point $X_{3}$ in the independent group $X 3 \_A V$ obtained for variant 3_AV, the differences of the means turned out to be statistically significant for the level of significance assuming values $p(<0.0001 ; 0.002)$, compared with independent groups X3_Visual, X3_ECDIS, X3_Pmax and X3_Pprecise, obtained for variants 3_Visual, 3_ECDIS, 3_Pmax and 3_Pprecise of the Scenario 3 (Table 16). Thus, there was a basis for rejecting the hypothesis $\mathrm{H}_{0}$ stating the equality of the means in the examined independent groups.

Table 16. The falsification of the hypotheses on the equality of mean distributions of the random variable of the ferry distance from the assumed reference point.

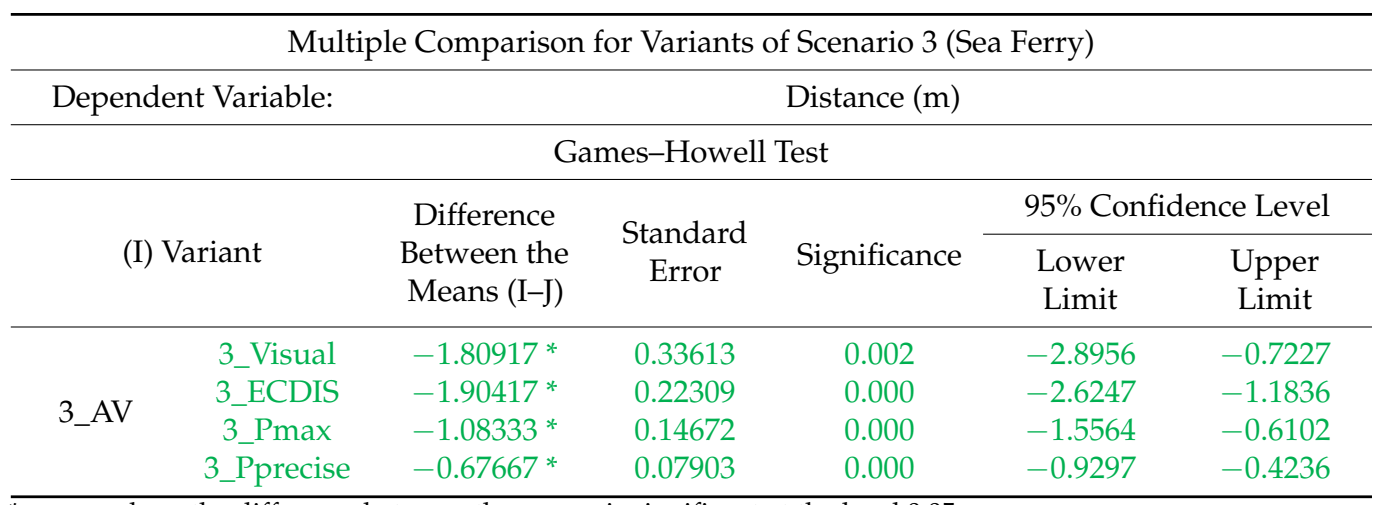

${ }^{*}$ green color-the difference between the means is significant at the level 0.05 .

\subsubsection{Analysis of Multiple Comparisons of the Parameters in Scenario 4. Cruise Ship}

Similar values of the significance level of test statistics were observed for the cruise ship variant in passages using the decision support system with AV-based navigational information display.

For the distributions of the random variable of the primary criterion, i.e., the distances $X_{4}$ of the sea ferry from the eastern berth of Gryfia Island in the independent group $\mathrm{X} 4 \mathrm{AV}$, the differences of the means turned out to be significant for the level assuming values $p<0.0001$, compared with independent groups X4_Visual, X4_ECDIS, X4_Pmax and X4_Pprecise, obtained for variants 4_Visual, 4_ECDIS, 4_Pmax and 4_Pprecise, of Scenario 4 (Table 17). Thus, there was a basis for rejecting hypothesis $\mathrm{H}_{0}$ stating the equality of the means in the examined independent groups.

Table 17. The falsification of the hypotheses on the equality of means of the random variable: distance of the cruise ship from the east berth of Gryfia Island.

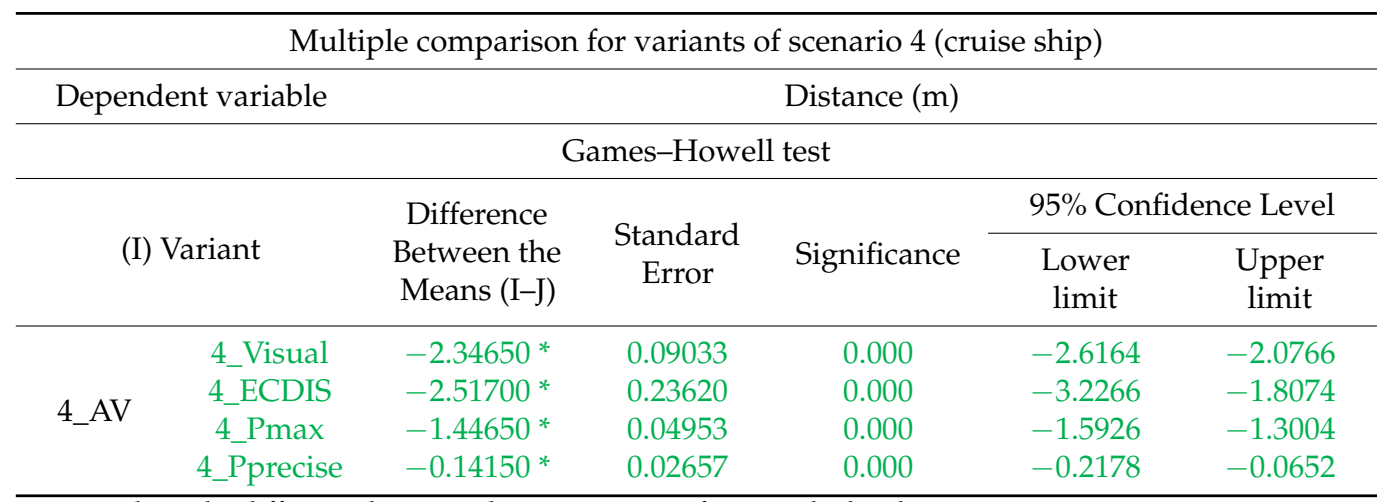




\section{Conclusions}

Summarizing the results of statistical tests conducted for ship passage variants using the AV system in the particular scenarios of the simulation experiment, we can see that:

1. In Scenario 1 for the container ship:

a. The mean distributions of the resultant speed at the moment of container ship's contact with the fender are not statistically different from the mean distribution of the same variable obtained for variants of passages using only visual observation and the other tested systems.

b. The use of the author's AV system during parallel (alongside) berthing of the container ship does not significantly reduce the resultant speed at the moment of the hull's contact with the fender.

c. The mean distribution of maneuvering time does not differ significantly from the mean distributions of the same variable obtained for the variants using only visual observation and other systems.

d. The use of the AV system developed by this author during parallel berthing of the container ship was not statistically significant for the reduction of maneuvering time.

2. In Scenario 2 for the general cargo ship:

a. The mean distribution of the resultant speed at the moment of the general cargo ship's contact with the fender is statistically different from the mean distribution of the same variable obtained for variants of passages using only visual observation and ECDIS and Pilot_max systems. The mean distribution of the resultant speed at the moment of the general cargo ship contact with the fender is not statistically different from the mean distribution of the same variable obtained for variants of passages using the Pilot_precise system.

b. The use of the AV system developed by this author during the diagonal berthing, using a spring line, significantly affects the reduction of resultant speed at the moment of the hull contact with the fender.

c. The mean distribution of maneuvering time differs significantly from the mean distribution of the same variable obtained for the variants using only visual observation and the ECDIS system. The mean distribution of maneuvering time is not statistically different from the mean distribution of the same variable obtained for the variants using the Pilot_max and Pilot_precise systems.

d. The use of the AV system developed by this author during the diagonal berthing, using a spring line, of the general cargo ship significantly affects the reduction of resultant speed at the moment of the hull contact with the fender.

3. In Scenario 3 for the sea ferry:

a. The mean distribution of the sea ferry distance from the assumed reference point is significantly different from the mean distribution of the same variable obtained for variants using only visual observation and the other tested systems.

b. The use of the AV system developed by this author during the berthing of the sea ferry significantly affects the reduction of the ship's hull distance from the assumed reference point.

4. In Scenario 4 for the cruise ship:

a. The mean distribution of the cruise ship distance from the east berth of Gryfia Island is significantly different from the mean distribution of the same variable obtained for variants using only visual observation and the other tested systems.

b. The use of the AV system developed by this author during the turning of the cruise ship significantly affects the reduction of the ship's hull distance from the assumed reference point.

5. In Scenario 5a,b for the tow train: 
a. The mean distribution of the distance of the tow train contour from the assumed reference point, during the turning maneuvering of unberthing and turning, statistically differs from the mean distribution of the same variable obtained for the same variants using the Pilot_precise system.

b. The use of the author's AV system during the unberthing and turning of the tow train significantly affects the reduction of the distance of the tow train contour points from the assumed reference point of the mean and maximum maneuvering area.

The assessment partly verifies the veracity of the hypothesis that the use of AV-based navigational information display in the decision support system will increase the efficiency and safety of navigation during maneuvering in a restricted area.

The analysis of the test results has shown that the use of AV-based navigational information display in the decision support system in most of the maneuvers performed has a significant impact on the safety of navigation in a restricted area.

The results of the simulation experiment indicate that the display of the real navigational situation by the AV method in five variants out of six increases navigational safety, while in the remaining variant, the difference of the values of the parameters of the compared criteria is not statistically significant (the mean distribution of resultant speed at the moment of the container ship contact with the fender and the random variable of maneuvering time do not differ significantly with the mean distribution of the same variables obtained for the variants using only visual observation and other systems).

The results of the analysis led to the formulation of the following general conclusions concerning the presented method:

6. It is possible to display a real navigational situation using $3 \mathrm{D}$ models of the ship and the environment generated in real-time.

7. The algorithms applied in the models enable the simulation of natural phenomena determining the real perception and assessment of the environment by the navigator.

8. The AV technology used in the method is applicable in restricted areas, not open waters.

9. The method enables the application of models used for the support of the navigator's decision that are unavailable (cannot be implemented) in current solutions.

10. The method has no significant impact on navigational safety indicators (it does not increase the situational awareness of the navigator) when:

a. the place of ship's hull contact with the collision object remains within the sight range and is visible for the navigator;

b. the lines of cross- and longitudinal sections of the hull and the collision object in the surroundings at the point of contact have an uncomplicated, exactly or roughly rectangular shape.

11. The method has a significant impact on navigational safety indicators (enhances the situational awareness of the navigator) when:

a. the place of ship's hull contact with the collision object is not in the observer's sight (is in an obscured or inaccessible place) or the prevailing conditions of reduced visibility exclude visual observation;

b. the lines of cross- and longitudinal sections of the hull and the collision object in the surroundings at the point of contact have a complex shape, different from the rectangle or where in the orthogonal top view, the edge of the ship's contact with the collision object is obscured by any sectional plane (of the ship or object).

The developed method of AV-based navigational information display is universal and has wide applicability because:

1. it can be applied in any integrated navigational system for the dynamic visualization of a real navigational situation during maneuvering in a restricted area, including MASS; 
2. it can be applied in a navigational-maneuvering system for dynamic visualization of the simulated navigational situation in the process of navigators' training.

3. prototype of the system with the implemented method has wide development potential. Possible modifications of the developed system architecture (the developed prototype is a basic version, due to the limitations of modern solutions used on ships and in port infrastructure) offer broad applicability in modern, future marine traffic engineering systems and UMV.

Author Contributions: Conceptualization, R.G.; methodology, R.G.; validation, R.G., B.M. and M.P.; formal analysis, M.P.; investigation, B.M.; data curation, R.G.; writing-original draft preparation, R.G., B.M.; writing—review and editing, B.M.; visualization, R.G. and B.M.; supervision, M.P.; project administration, R.G. All authors have read and agreed to the published version of the manuscript.

Funding: This research received no external funding.

Institutional Review Board Statement: Not applicable.

Informed Consent Statement: Not applicable.

Data Availability Statement: Data available on request from the authors.

Conflicts of Interest: The authors declare no conflict of interest.

\section{References}

1. Levander, O. Autonomous ships on the high seas. IEEE Spectr. 2017, 54, 26-31. [CrossRef]

2. Rødseth, Ø.J.; Nordahl, H. Definition of autonomy levels for merchant ships. In NFAS, Norwegian Forum for Autonomous Ships; NFAS: Trondheim, Norway, 2018; Volume 2. [CrossRef]

3. Miller, A.; Rybczak, M.; Rak, A. Towards the Autonomy: Control Systems for the Ship in Confined and Open Waters. Sensors 2021, 21, 2286. [CrossRef] [PubMed]

4. Final Report Summary-MUNIN (Maritime Unmanned Navigation through Intelligence in Networks)। Report Summary | MUNIN I FP7 ICORDIS I European Commission. Available online: https://cordis.europa.eu/project/id/314286 / reporting/pl (accessed on 15 June 2021).

5. Rakuten Group Inc. Rakuten Institute of Technology and Maritime Robotics Agree to Collaborate on Research into Unmanned Cargo Ships. Available online: https://global.rakuten.com/corp/news/press/2018/0313_02.html (accessed on 18 June 2021).

6. Burmeister, H.-C.; Bruhn, W.; Rødseth, Ø.J.; Porathe, T. Autonomous Unmanned Merchant Vessel and its Contribution towards the e-Navigation Implementation: The MUNIN Perspective. Int. J. E-Navig. Marit. Econ. 2014, 1, 1-13. [CrossRef]

7. Rødseth, Ø.J.; Burmeister, H.-C. Risk assessment for an unmanned merchant ship. TransNav Int. J. Mar. Navig. Saf. Sea Transp. 2015, 9, 357-364. [CrossRef]

8. Kretschmann, L.; Burmeister, H.-C.; Jahn, C. Analyzing the economic benefit of unmanned autonomous ships: An exploratory cost-comparison between an autonomous and a conventional bulk carrier. Res. Transp. Bus. Manag. 2017, 25, 76-86. [CrossRef]

9. NYK to Participate in Crewless Maritime Autonomous Surface Ship Trial Project. Available online: https://www.nyk.com/ english/news/2020/20200615_01.html (accessed on 20 June 2021).

10. Yara Birkeland. The First Zero Emission, Autonomous Ship, 2018. Yara International Web Site. Available online: https: / / www.yara.com/knowledge-grows/game-changer-for-the-environment/ (accessed on 15 June 2021).

11. Autonomous Ship Project, Key Facts about YARA Birkeland-Kongsberg Maritime. Available online: https://www.kongsberg. $\mathrm{com} / \mathrm{maritime} /$ support/themes/autonomous-ship-project-key-facts-about-yara-birkeland/?OpenDocument= (accessed on 15 September 2019).

12. The ReVolt. Available online: https://www.dnv.com/Default (accessed on 18 June 2021).

13. NYK Releases Partial Findings in Study on Avoiding Collisions I NYK Line. Available online: https: / / www.nyk.com/english/ news /2017/20171226_01.html (accessed on 18 June 2021).

14. NYK and MTI Participating Projects Selected as Support Projects for R\&D in Advanced Safety Technology of Vessels by MLIT I NYK Line. Available online: https:/ / www.nyk.com/english/news/2016/004366.html (accessed on 18 June 2021).

15. Jallal, C. Rolls-Royce and Finferries Demonstrate World's First Fully Autonomous Ferry. Marit. Digit. Commun. 2018. Available online: https: / / www.rolls-royce.com/media/press-releases/2018/03-12-2018-rr-and-finferries-demonstrate-worlds-first-fullyautonomous-ferry.aspx (accessed on 7 July 2021).

16. Autoferry-NTNU. Available online: https:/ / www.ntnu.edu/autoferry (accessed on 18 June 2021).

17. Maritime Journal I ABB Trials Autonomous Passenger Ferry. Available online: https://www.maritimejournal.com/news101 / onboard-systems/monitoring-and-control/abb-trials-autonomous-passenger-ferry (accessed on 18 June 2021).

18. Bolbot, V.; Theotokatos, G.; Boulougouris, E.; Wennersberg, L.A.L.; Nordahl, H.; Rødseth, Ø.J.; Faivre, J.; Colella, M.M. Paving the way toward autonomous shipping development for European Waters-The AUTOSHIP project. In Autonomous Ships; Royal Institution of Naval Architects: London, UK, 2020; ISBN 978-1-911649-06-9. 
19. Blanke, M.; Henriques, M.; Bang, J. A Pre-Analysis on Autonomous Ships; Technical University of Denmark: Lyngby, Denmark, 2017.

20. Peeters, G.; Yayla, G.; Catoor, T.; Van Baelen, S.; Afzal, M.R.; Christofakis, C.; Storms, S.; Boonen, R.; Slaets, P. An Inland Shore Control Centre for Monitoring or Controlling Unmanned Inland Cargo Vessels. J. Mar. Sci. Eng. 2020, 8, 758. [CrossRef]

21. Wärtsilä Remote Controls an $80 \mathrm{~m}$ Ship from $8000 \mathrm{~km}$ Away. Available online: https://www.wartsila.com/twentyfour7 /innovation/wartsila-remote-controls-an-80-m-ship-from-8000-km-away (accessed on 15 September 2019).

22. Samsung Heavy Industries Completes Autonomous Tug Tests. Smart Marit. Netw. 2020. Available online: https: //smartmaritimenetwork.com/2020/10/19/samsung-heavy-industries-completes-autonomous-tug-tests/ (accessed on 7 July 2021).

23. Abu Dhabi Ports to Develop Unmanned Autonomous Tugs with Robert Allan. Available online: https:/ / www.seatrade-maritime. com/technology/abu-dhabi-ports-develop-unmanned-autonomous-tugs-robert-allan (accessed on 18 June 2021).

24. Ryste, A.-M.T.; Moen, L.K. Autonomous Vessels-Concept in the Making. Mar. Eng. 2020, 55, 730-735. [CrossRef]

25. Crainic, T.G.; Guajardo, M.; Roy, D.; Wallace, S. Editorial to the Special Issue on Transportation and Logistics with Autonomous Technologies. Int. Trans. Oper. Res. 2021, 28, 1619-1625. [CrossRef]

26. Gu, Y.; Goez, J.C.; Guajardo, M.; Wallace, S.W. Autonomous vessels: State of the art and potential opportunities in logistics. Int. Trans. Oper. Res. 2021, 28, 1706-1739. [CrossRef]

27. Akbar, A.; Aasen, A.K.; Msakni, M.K.; Fagerholt, K.; Lindstad, E.; Meisel, F. An economic analysis of introducing autonomous ships in a short-sea liner shipping network. Int. Trans. Oper. Res. 2021, 28, 1740-1764. [CrossRef]

28. Maskooki, A.; Virjonen, P.; Kallio, M. Assessing the prediction uncertainty in a route optimization model for autonomous maritime logistics. Int. Trans. Oper. Res. 2021, 28, 1765-1786. [CrossRef]

29. Lloyd's Register Design Code for Unmanned Marine Systems. 2017. Available online: https://www.lr.org/en/unmanned-code/ (accessed on 7 July 2021).

30. Laurinen, M. Remote and Autonomous Ships: The Next Steps. AAWA: Advanced Autonomous Waterborne Applications; Rolls-Royce: London, UK, 2016.

31. MSC 99/5/6. Considerations on Definitions for Levels and Concepts of Autonomy; Regulatory Scoping Exercise for the Use of Maritime Autonomous Surface Ships (Mass); IMO: London, UK, 2018.

32. IMO. MSC 100/5/1. Proposal for a Classification Scheme for Degrees of Autonomy; Regulatory Scoping Exercise for the Use of Maritime Autonomous Surface Ships (MASS); IMO: London, UK, 2018.

33. MSC.1/Circ.1638. Outcome of the Regulatory Scoping Exercise for the Use of Maritime Autonomous Surface Ships (MASS); Regulatory Scoping Exercise for the Use of Maritime Autonomous Surface Ships (Mass); IMO: London, UK, 2021.

34. MSC.1/Circ.1604. Interim Guidelines For Mass Trials; Regulatory Scoping Exercise for the Use of Maritime Autonomous Surface Ships (Mass); IMO: London, UK, 2019.

35. DNV. Autonomous and Remotely Operated Ships; DNV: Oslo, Norway, 2018.

36. European Maritime Safety Agency VTMIS. Eu Operational Guidelines For Safe, Secure And Sustainable Trials Of Maritime Autonomous Surface Ships (MASS); EMSA: Lisbon, Portugal, 2020.

37. ClassNK. ClassNK Guidelines for Automated/Autonomous Operation of Ships; ClassNK: Tokyo, Japan, 2020.

38. Kari, R.; Steinert, M. Human Factor Issues in Remote Ship Operations: Lesson Learned by Studying Different Domains. J. Mar. Sci. Eng. 2021, 9, 385. [CrossRef]

39. Yoshida, M.; Shimizu, E.; Sugomori, M.; Umeda, A. Regulatory Requirements on the Competence of Remote Operator in Maritime Autonomous Surface Ship: Situation Awareness, Ship Sense and Goal-Based Gap Analysis. Appl. Sci. 2020, 10, 8751. [CrossRef]

40. Yoshida, M.; Shimizu, E.; Sugomori, M.; Umeda, A. Identification of the Relationship between Maritime Autonomous Surface Ships and the Operator's Mental Workload. Appl. Sci. 2021, 11, 2331. [CrossRef]

41. Dudojc, B.; Mindykowski, J. New Approach to Analysis of Selected Measurement and Monitoring Systems Solutions in Ship Technology. Sensors 2019, 19, 1775. [CrossRef] [PubMed]

42. Man, Y.; Lundh, M.; Porathe, T.; MacKinnon, S. From Desk to Field-Human Factor Issues in Remote Monitoring and Controlling of Autonomous Unmanned Vessels. Procedia Manuf. 2015, 3, 2674-2681. [CrossRef]

43. NAV 58/14. Development of an E-Navigation Strategy Implementation Plan; Report To The Maritime Safety Committee; IMO: London, UK, 2012.

44. Porathe, T. Remote Monitoring and Control of Unmanned Vessels-The MUNIN Shore Control Centre. In Proceedings of the 13th International Conference on Computer Applications and Information Technology in the Maritime Industries (COMPIT '14), Redworth, UK, 12-14 May 2014; pp. 460-467.

45. Ottesen, A.E. Situation Awareness in Remote Operation of Autonomous Ships. Shore Control Cent. Guidel. Nor. 2014. Available online: https: / www.ntnu.no/documents/10401/1264435841/Artikkel+Are+E+Ottesen.pdf/abb533ae-e73a-489e-80ec-f0e198 e72c0a (accessed on 7 July 2021).

46. Gralak, R. A Method of Navigational Information Display Using Augmented Virtuality. J. Mar. Sci. Eng. 2020, 8, 237. [CrossRef]

47. Gucma, S.; Zalewski, P. Optimization of fairway design parameters: Systematic approach to manoeuvring safety. Int. J. Nav. Archit. Ocean Eng. 2020, 12, 129-145. [CrossRef] 